\title{
Targeting the phosphatidylinositol 3-kinase/Akt/mechanistic target of rapamycin signaling pathway in B-lineage acute lymphoblastic leukemia: An update
}

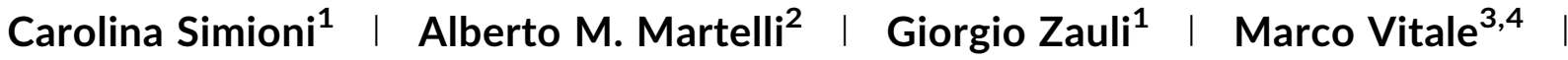 \\ James A. McCubrey ${ }^{5}$ | Silvano Capitani ${ }^{1}$ | Luca M. Neri ${ }^{1}$ (D)
}

${ }_{1}^{1}$ Department of Morphology, Surgery and Experimental Medicine, University of Ferrara, Ferrara, Italy

2 Department of Biomedical and Neuromotor Sciences, University of Bologna, Bologna, Italy

${ }^{3}$ Department of Medicine and Surgery,

University of Parma, Parma, Italy

${ }^{4}$ CoreLab, Azienda Ospedaliero-Universitaria

di Parma, Parma, Italy

${ }^{5}$ Department of Microbiology and Immunology, Brody School of Medicine, East

Carolina University, Greenville, North Carolina

\section{Correspondence}

Luca M. Neri and Silvano Capitani, Department of Morphology, Surgery and Experimental Medicine, University of Ferrara, Italy.

Email: luca.neri@unife.it (L.M.N);

silvano.capitani@unife.it (S.C)
Despite considerable progress in treatment protocols, B-lineage acute lymphoblastic leukemia (B-ALL) displays a poor prognosis in about $15-20 \%$ of pediatric cases and about $60 \%$ of adult patients. In addition, life-long irreversible late effects from chemoand radiation therapy, including secondary malignancies, are a growing problem for leukemia survivors. Targeted therapy holds promising perspectives for cancer treatment as it may be more effective and have fewer side effects than conventional therapies. The phosphatidylinositol 3-phosphate kinase (PI3K)/Akt/mechanistic target of rapamycin (mTOR) signaling pathway is a key regulatory cascade which controls proliferation, survival and drug-resistance of cancer cells, and it is frequently upregulated in the different subtypes of B-ALL, where it plays important roles in the pathophysiology, maintenance and progression of the disease. Moreover, activation of this signaling cascade portends a poorer prognosis in both pediatric and adult B-ALL patients. Promising preclinical data on PI3K/Akt/mTOR inhibitors have documented their anticancer activity in B-ALL and some of these novel drugs have entered clinical trials as they could lead to a longer event-free survival and reduce therapy-associated toxicity for patients with B-ALL. This review highlights the current status of $\mathrm{PI} 3 \mathrm{~K} / \mathrm{Akt} / \mathrm{mTOR}$ inhibitors in B-ALL, with an emphasis on emerging evidence of the superior efficacy of synergistic combinations involving the use of traditional chemotherapeutics or other novel, targeted agents.

\section{KEYWORDS}

B-ALL, combination therapy, PI3K/Akt/mTOR signaling, protein kinase inhibitors, targeted therapy

\section{1 | INTRODUCTION}

B-lineage acute lymphoblastic leukemia (B-ALL) is a hematological malignancy characterized by the uncontrolled proliferation of B-cell

Carolina Simioni and Alberto M. Martelli equally contributed to this article. precursors. B-ALL displays a bimodal distribution with approximately $60 \%$ of cases occurring in patients younger than 20 years of age and accounting for roughly $80 \%$ of pediatric leukemias (Pui, Relling, \& Downing, 2004). The second peak occurs around the fifth decade of life, however it accounts for only $20 \%$ of leukemias diagnosed in adult patients. At present, $95 \%$ of pediatric B-ALL patients reach a complete remission (CR), while the estimated 5-year survival rates 
(EFS) are 85-90\% (Pui et al., 2004; Pui et al., 2014). As to adults, they have $C R$ rates of about $85 \%$, however their 5 -year survival rate is $40 \%$ overall and approximately $7 \%$ for patients who experience relapse (Fielding et al., 2007; Goldstone et al., 2008). Indeed, adults are at a higher risk of relapse due to disease factors present at diagnosis, including the Philadelphia chromosome $(\mathrm{Ph})$ formed upon the $\mathrm{t}(9 ; 22)$ reciprocal translocation that fuses the breakpoint cluster region $(\mathrm{Bcr})$ gene with the Abelson tyrosine kinase (Abl) (Lafage-Pochitaloff et al., 2017). The incidence of $\mathrm{Ph}^{+} \mathrm{B}-\mathrm{ALL}$ increases with age and occurs in up to $50 \%$ of B-ALL diagnosed in individuals $\geq 50$ year old (Pui \& Evans, 2006). Depending on the translocation breakpoint in Bcr, different Bcr-Abl isoforms are expressed, which all contain exons 2-11 of the $\mathrm{Abl}$ gene, but different lengths of their Bcr component (Deininger, Goldman, \& Melo, 2000). The most common Bcr-Abl isoforms are p190 (alternatively named: p185) and p210. While p210 is the hallmark of chronic myelogenous leukemia, p190 occurs in the majority of $\mathrm{Ph}^{+}$ B-ALL. It is intriguing that, very recently, marked differences in the interactome and tyrosine phosphoproteome of p190 and p210 Bcr-Abl isoforms were found (Cutler et al., 2017; Reckel et al., 2017). Besides other aspects, these findings could give important indications regarding differential sensitivity to kinase inhibitors and other targeted agents.

Philadelphia chromosome-like B-ALL (Ph-like B-ALL) is a recently identified high-risk B-ALL subtype. It occurs more frequently in adolescent and adult patients, having been reported in as many as $27 \%$ of young adults with B-ALL between 21 and 39 years of age, while only $10 \%$ of childhood B-ALL cases are Ph-like (Tran \& Loh, 2016). This aggressive $B-A L L$ subtype is characterized by a gene expression profile similar to that of $\mathrm{Ph}^{+} \mathrm{B}-\mathrm{ALL}$, however the $\mathrm{Bcr}-\mathrm{Abl}$ fusion protein is not expressed. Nevertheless, Ph-like B-ALL cells harbor a multitude of genetic alterations that activate several cytokine receptor genes and kinase signaling pathways resulting in a consequent poor prognosis (Ofran \& Izraeli, 2017).

Although in childhood B-ALL patients multiagent chemotherapy has had a great success, the same is not true in adults, even with the introduction of tyrosine kinase inhibitors (TKIs) targeting Bcr-Abl kinase, in combination with chemotherapy (Malagola, Papayannidis, \& Baccarani, 2016).

Moreover, in refractory or relapsed settings, the outcome of pediatric B-ALL is still poor (Pui \& Evans, 2006). Furthermore, the longterm adverse effects of polychemotherapy and radiotherapy increase the risk of morbidity and premature death, especially in children (Ness, Armenian, Kadan-Lottick, \& Gurney, 2011). Therefore, the identification of novel targeted therapies for supporting conventional chemotherapy is urgently needed to further improve the outcome of B-ALL in both adult and pediatric patients (Dias, Kenderian, Westin, \& Litzow, 2016).

A promising candidate for the development of targeted therapies is the phosphatidylinositol kinase (PI3K)/Akt/mechanistic target of rapamycin (mTOR) pathway. This signaling cascade is involved in a wide array of physiological processes whose deregulation is frequently associated with tumorigenesis, including mRNA translation, apoptosis, autophagy, metabolism, migration, and angiogenesis (Pons-Tostivint, Thibault, \& Guillermet-Guibert, 2017; Bahrami et al., 2018).

Overall, this pathway is one of the most frequently mutated and aberrantly activated networks in different types of cancers (GuerreroZotano, Mayer, \& Arteaga, 2016), including acute leukemias (Bertacchini et al., 2015). For this reason, pharmaceutical companies have developed many selective inhibitors of the key effectors of this complex signaling cascade (Rodon \& Tabernero, 2017). However, a growing body of evidence indicates that small molecules targeting $\mathrm{PI} 3 \mathrm{~K} / \mathrm{Akt} / \mathrm{mTOR}$ signaling are most effective against cancer cells when used in combination with other therapeutic agents.

Aberrant activity of the PI3K/Akt/mTOR network is commonly detected in adult B-ALL (Gomes et al., 2014), while pathway activation is associated with poor prognosis and chemoresistance in pediatric BALL cases (Morishita et al., 2012; Nemes et al., 2013), and high expression of mTOR has been very recently demonstrated to correlate with a poor clinical outcome in both adult and childhood B-ALL (Khanna et al., 2017). Moreover, glycogen synthase kinase-3 $\beta$ (GSK$3 \beta$ ), an Akt downstream target (Hermida, Dinesh Kumar, \& Leslie, 2017), is a negative prognostic indicator in acute leukemias, including childhood B-ALL (Ruvolo, 2017; Tovar, Zeron, Romero, Sanchez, \& Romero, 2016). These findings have provided a rationale for exploring the efficacy in the clinic of small molecules targeting this pathway in association with chemotherapy in B-ALL patients (Daver et al., 2015).

In this article, following a brief overview of what is known about $\mathrm{PI3K} / \mathrm{Akt} / \mathrm{mTOR}$ signaling in general and in B-ALL in particular, we will summarize the recent advances on its relevance as a potential therapeutic target in the various subtypes of B-ALL, with a particular emphasis on the combinatorial use of $\mathrm{PI} 3 \mathrm{~K} / \mathrm{Akt} / \mathrm{mTOR}$ inhibitors as novel therapeutic strategies.

\section{2 | PI3K/Akt/mTOR SIGNALING}

The PI3K family comprises lipid kinases that phosphorylate the $3^{\prime}-\mathrm{OH}$ of the inositol ring. PI3K isoforms are grouped into three classes, displaying distinct substrate specificity, and lipid products (Cantley, 2002). For the scopes of this review, we will mainly focus on class I $\mathrm{PI} 3 K$ s as they are the best understood and the most widely implicated in human malignancies (Engelman, Luo, \& Cantley, 2006; Millis, Ikeda, Reddy, Gatalica, \& Kurzrock, 2016). Class I PI3Ks phosphorylate phosphatidylinositol-4,5-bisphosphate (PIP2) to yield phosphatidylinositol-3,4,5-trisphosphate (PIP3). Class I PI3Ks are divided into two subgroups: A and B. Class IA PI3Ks contain one of three catalytic subunits ( $p 110 a, p 110 \beta, p 110 \delta)$ that form heterodimers with one of the five adaptor/regulatory isoforms (p85a, p85 $\beta$, p55a, p55 $\gamma, p 50 a$ ). Class IA PI3Ks are activated downstream of either tyrosine kinase receptors (TKRs) or G protein-coupled receptors (GPCRs). The single class IB PI3K comprises the p110 $\gamma$ catalytic subunit which binds one of two related regulatory subunits, either p101 or p87. Class IB PI3Ks mainly act downstream of GPCRs, however they can be stimulated by TKRs (Franke, 2008; Vanhaesebroeck, Guillermet-Guibert, Graupera, \& Bilanges, 2010). Upon activation by growth factors, hormones, and 
cytokines, class I PI3Ks initiate a cascade of events that promote cancer cell proliferation, survival, migration, drug-resistance, and glycolytic metabolism.

Class II PI3Ks can be activated by TKRs, cytokine receptors and integrins, however their specific functions in cancer are still not well understood (Falasca et al., 2017).

Class III PI3K comprises only a heterodimeric enzyme consisting of a catalytic (Vps34) and an adaptor (p150) subunit (Yu, Long, \& Shen, 2015). Vps34 is implicated in the regulation of autophagy in response to cellular stresses.

Akt is a serine/threonine kinase belonging to the AGC protein kinase family. Akt is a critical effector of $\mathrm{PI} 3 \mathrm{~K}$ in carcinogenesis, as documented by the fact that about 400 proteins contain the consensus sequence for Akt phosphorylation. The heterogeneity of proteins potentially phosphorylated by Akt supports the its key role in cell cycle progression, survival, mRNA translation, glycolysis, and angiogenesis (Manning \& Toker, 2017; Martini, De Santis, Braccini, Gulluni, \& Hirsch, 2014).

The recruitment of inactive Akt from the cytosol to the plasma membrane requires that the pleckstrin homology $(\mathrm{PH})$ domain of Akt binds to PIP3 synthesized by PI3K. Akt is then phosphorylated at Thr 308 by phosphatidylinositol-dependent kinase 1 (PDK1) and at Ser 473 by mTOR complex 2 (mTORC2), resulting in full activation of Akt activity (Georgescu, 2010).

mTOR is a serine/threonine kinase which belongs to the PI3Krelated kinase (PIKK) family (Memmott \& Dennis, 2009; Shen et al., 2018). mTOR is the catalytic subunit of two distinct multiprotein complexes, referred to as mTOR complex 1 (mTORC1) and mTORC2, which display different sensitivity to rapamycin and differ in their protein composition.

mTORC1 is characterized by the interactions between mTOR and the regulatory associated protein of mTOR (Raptor) which regulates mTOR activity and functions as a scaffold for recruiting mTORC1 substrates. This complex also comprises DEP-domaincontaining mTOR interacting protein (Deptor), prolin-rich Akt substrate $40-k D a$ (PRAS40), mammalian lethal with Sec13 protein 8 (mLST8), and Tti1/Tel2.

mTORC1 is sensitive to rapamycin and its analogs (rapalogs) that are allosteric mTORC1 inhibitors and do not target the mTOR catalytic site (Alayev \& Holz, 2013; Kim et al., 2002; Oshiro et al., 2004). mTORC1 controls translation in response to growth factors/nutrients through the phosphorylation of p70S6 kinase (p70S6K) and 4E-BP1 (Browne \& Proud, 2004; Ma \& Blenis, 2009; Shahbazian et al., 2010). Importantly, mTORC1 represses autophagy, a lysosome-dependent degradation pathway which allows cells to recycle damaged or superfluous cytoplasmic content (Chen et al., 2010; Fu et al., 2017, 2018). As a consequence, cells produce metabolic precursors for macromolecular biosynthesis or ATP generation. In cancer cells, autophagy fulfills a dual role, because it can display both tumorsuppressing and tumor-promoting functions. Indeed, the autophagic machinery prevents necrosis and inflammation, that can lead to genetic instability and tumorigenesis (Galluzzi, Bravo-San Pedro, Levine, Green, \& Kroemer, 2017; Sugiyama et al., 2017; Wang, Zhang,
Luo, Ning, \& Fang, 2018). However, autophagy may be important for cancer progression, by providing energy through its recycling mechanism during unfavorable metabolic circumstances, that are very common encountered by tumor cells (Janku, McConkey, Hong, \& Kurzrock, 2011; Won et al., 2018).

mTORC2 comprises the rapamycin-insensitive companion of mTOR (Rictor), Deptor, protein observed with rictor-1 (Protor-1), $\mathrm{mLST} 8$, mammalian stress-activated protein kinase interacting protein (mSIN1), and Tti1/Tel2. mTORC2 is generally described as being insensitive to rapamycin/rapalogs. However, long-term (>24 hr) treatment of cancer cells with rapamycin/rapalogs could result in mTORC2 activity inhibition (Dunlop \& Tee, 2009; Rosner \& Hengstschlager, 2008).

mTORC1 activity is quite well understood and is mainly regulated thorugh PI3K/Akt signaling (Ilagan \& Manning, 2016), although MEK/ ERK could be also involved (Zeng et al., 2018).

In contrast, the mechanisms that control mTORC2 have only begun to be revealed (Sparks \& Guertin, 2010), however mTORC2 activation by growth factors requires $\mathrm{PI} 3 \mathrm{~K}$, as pharmacological inhibition of PI3K decreased mTORC2 activity in vitro (Huang, Dibble, Matsuzaki, \& Manning, 2008; Liu et al., 2015).

$\mathrm{PI} 3 \mathrm{~K}, \mathrm{Akt}$, and $\mathrm{mTORC} 1 / 2$ are linked to each other via regulatory feedback loops that restrain their simultaneous hyperactivation (Dunlop \& Tee, 2009). A negative regulation of Akt activity by mTORC1 is dependent on p70S6K-mediated phosphorylation of insulin receptor substrate (IRS) -1 and -2 adaptor proteins, downstream of the insulin receptor (IR) or insulin-like growth factor1 receptor (IGF-1R) (Bhaskar and Hay, 2007; Lang et al., 2010; Shah, Wang, \& Hunter, 2004). IRS-1 and IRS-2 are normally required to activate class IA PI3Ks after stimulation of IR/IGF-1R tyrosine kinase activity. When mTORC1 is active, p70S6K phosphorylates IRS-1/-2 on Ser residues, targeting them for proteasomal degradation (Sriburi, Jackowski, Mori, \& Brewer, 2004; Xu et al., 2008). Therefore, mTORC1 signaling inhibition by rapamycin/rapalogs blocks this negative feedback loop and hyperactivates Akt through PI3K and PDK1 (Alayev et al., 2017; Bertacchini et al., 2014).

$\mathrm{PI} 3 \mathrm{~K} / \mathrm{Akt} / \mathrm{mTOR}$ network function is mainly controlled by inositol lipid phosphatases (Rodgers, Ferguson, Mitchell, \& Ooms, 2017). In particular, phosphatase and tensin homolog deleted on chromosome 10 (PTEN) is a major negative regulator of the newtwork as it removes the $3^{\prime}$-phosphate from PIP3, thereby antagonizing PI3K signaling (Xie, Naizabekov, Chen, \& Tokay, 2016).

\section{3 | THE PI3K/Akt/mTOR PATHWAY IN B-ALL}

Activation of $\mathrm{PI} 3 \mathrm{~K} / \mathrm{Akt} / \mathrm{mTOR}$ signaling is a common event in B-ALL cell lines and patient samples.

In $\mathrm{Ph}^{+}$leukemic cells, PI3K activation is dependent on the presence of a multiprotein complex that, besides p110 and p85 PI3K, comprises $\mathrm{Bcr}-\mathrm{Abl}$, its substrate $\mathrm{c}-\mathrm{CBL}$ (i.e., the cellular homolog of the v-Cbl oncoprotein [Brehme et al., 2009]), and the adaptor proteins, 
CRKL and c-CRK (Gotoh, Miyazawa, Ohyashiki, \& Toyama, 1994; Sattler et al., 1996; Skorski et al., 1995). The leukemogenic potential of activated $\mathrm{PI} 3 \mathrm{~K}$ is supported by the evidence that deletion of both Pik3r1 and Pik3r2 (which encode for class IA PI3K p85a and p85ß, respectively [Vanhaesebroeck, Vogt, \& Rommel, 2010]) markedly impaired leukemic transformation in a murine model of $\mathrm{Ph}^{+} \mathrm{B}-\mathrm{ALL}$ (Kharas et al., 2004, 2008). Other models of activation of $\mathrm{PI3K}$ in $\mathrm{Ph}^{+} \mathrm{B}$ ALL have been proposed, including Src family kinases, Ras, and IRS-1 (Kharas \& Fruman, 2005).

Downregulation of PTEN gene expression has been observed in a $\mathrm{Bcr}$-Abl-expressing murine pre-B-cell line, whereas PTEN overexpression delayed $\mathrm{Ph}^{+} \mathrm{B}-\mathrm{ALL}$ development in mice (Peng et al., 2010). Nevertheless, these results could not be confirmed using primary samples from adult patients with $\mathrm{Ph}^{+} \mathrm{B}-\mathrm{ALL}$. However, in human $\mathrm{Ph}^{+}$ B-ALL PTEN, although expressed, is functionally inactivated (see further on). The mechanisms of PI3K/Akt/mTOR signaling activation in $\mathrm{Ph}^{+} \mathrm{B}-\mathrm{ALL}$ are highlighted in Figure 1a.

Regarding $\mathrm{Ph}^{-} \mathrm{B}-\mathrm{ALL}$, evidence suggests that upregulation of the PI3K/Akt/mTOR network could be dependent on constitutively active pre-B-cell receptor (pre-BCR) signaling that characterizes approximately $13 \%$ of $\mathrm{Ph}^{-} \mathrm{B}-\mathrm{ALL}$ cases, whereas most $\mathrm{Ph}^{-} \mathrm{B}-\mathrm{ALL}$ cases lack expression of functional pre-BCR (Eswaran et al., 2015; Geng et al., 2015). However, it is unclear how active pre-BCR could positively impact on $\mathrm{PI3K} / \mathrm{Akt} / \mathrm{mTOR}$ activity. Given that pre-BCR ${ }^{+}$ $B-A L L$ patients exhibit significantly higher expression and activity of Src family kinases, it might be that upregulation of the PI3K/Akt/ mTOR cascade involves Syk, Fyn, or Lyn kinases (Geng et al., 2015; Kohrer et al., 2016). Moreover, expression and activity of PTEN were low in pre-BCR ${ }^{+}$B-ALL cells (Geng et al., 2015).

Interleukin-7 (IL-7) and IL-7 receptor (IL-7R) are essential for normal lymphocyte development and homeostasis, whereas aberrant IL-7/IL7R-mediated signaling promotes leukemogenesis (Oliveira et al., 2017). Interestingly, in $\mathrm{Ph}^{-} \mathrm{B}-\mathrm{ALL}$ gain-of-function mutations in IL-7Ra were associated with the aberrant expression of cytokine receptor-like factor 2 (CRLF2). Mutant IL-7Ra formed a functional receptor with CRLF2 for thymic stromal lymphopoietin (TSLP), which is closely related to IL-7 (Shochat et al., 2011, 2014). Although no evidence was provided that these mutations would
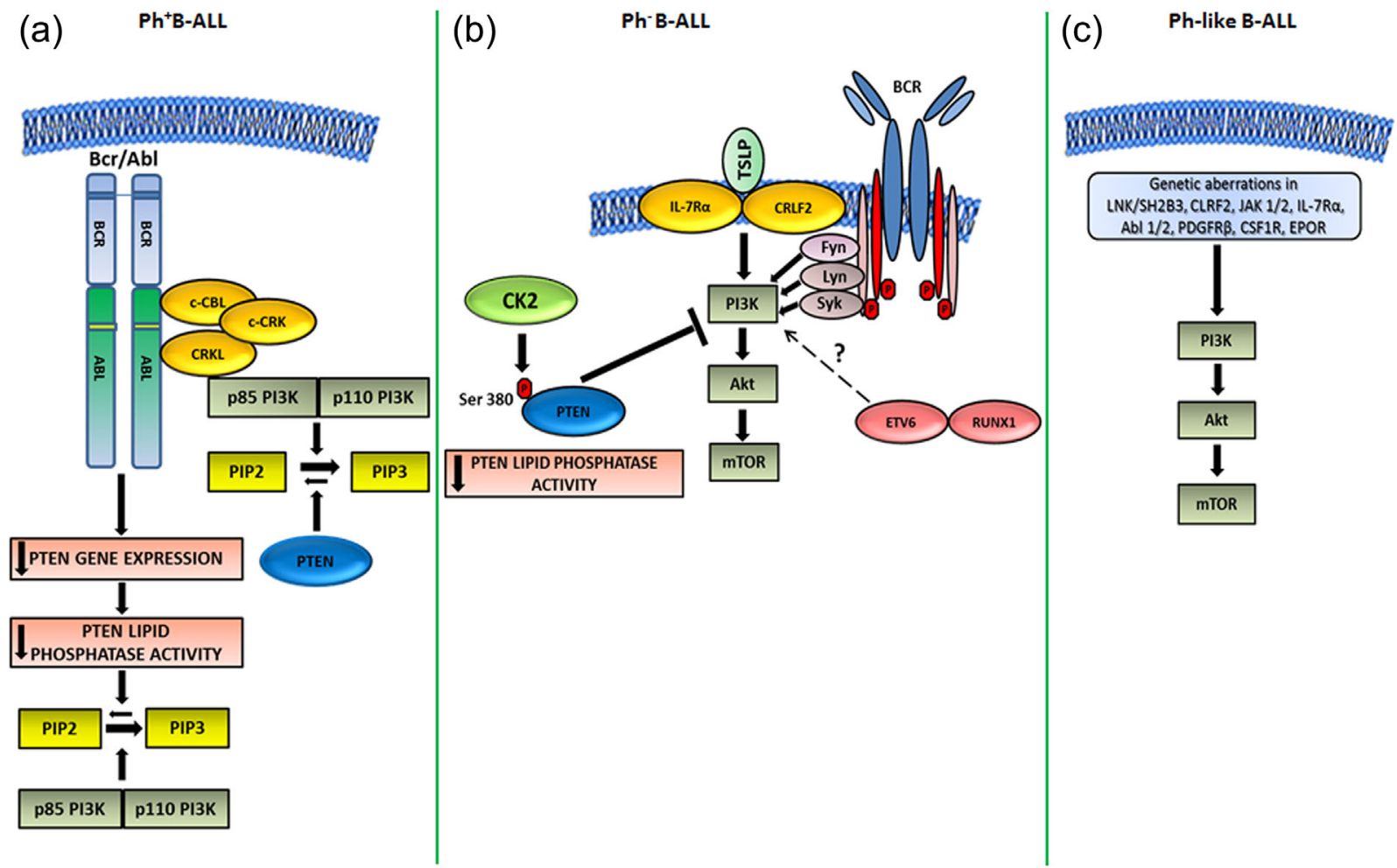

FIGURE 1 Mechanisms of PI3K/Akt/mTOR signaling activation in B-ALL subtypes. (a) $\mathrm{Ph}^{+} \mathrm{B}-\mathrm{ALL}$. In this subtype, the Bcr-Abl substrate, c-CBL, forms a multimeric complex consisting of Bcr-Abl itself, both p85 and p110 PI3K, as well as the adaptor proteins, CRKL and C-CRK. The complex increases PIP3 production from PIP2 through PI3K activity (Sattler et al., 1996). In a murine model of Ph ${ }^{+}$B-ALL, it has also been reported that Bcr-Abl downregulated PTEN gene expression, which resulted in increased levels of PIP3 (Peng et al., 2010). However, this mechanism of activation has not been confirmed using primary human $\mathrm{Ph}^{+} \mathrm{B}-\mathrm{ALL}$ samples, where PTEN protein was upregulated but functionally inhibited (Gomes et al., 2014). (b) $\mathrm{Ph}^{-} \mathrm{B}-\mathrm{ALL}$. In this subset of B-ALL, the aberrant upregulation of the PI3K/Akt/mTOR network could be due to TSLP/mutated IL-7Ra/CRLF2 signaling (Shochat et al., 2011, 2014), ETV6/RUNX1 fusion gene (Fuka et al., 2012), disregulated pre-BCR signaling through Fyn, Lyn, or Syk kinases (Geng et al., 2015; Kohrer et al., 2016), or increased CK2 activity ensuing in PTEN phosphorylation and inhibition of its lipid phosphatase activity on PIP3 (Gomes et al., 2014). (c) Ph-like B-ALL. Here, multiple genetic aberrations of LNK/SH2B3, CLRF2, JAK 1/2, IL-7Ra, Abl 1/2, PDGFRB, CSF1R, and EPOR have the potential for activating PI3K/Akt/mTOR signals (Tasian et al., 2017) 
result in $\mathrm{PI3K} / \mathrm{Akt} / \mathrm{mTOR}$ signaling activation, it is worth highlighting here that findings from other groups documented how TSLP promoted B-ALL cell survival and proliferation through the upregulation of the PI3K/Akt/mTOR network (Brown et al., 2007; Tasian et al., 2012). It is therefore plausible that IL-7Ra mutations could be one of the determinants of aberrant activation of the PI3K/ Akt/mTOR cascade in $\mathrm{Ph}^{-} \mathrm{B}-\mathrm{ALL}$.

The ETV6/RUNX1 fusion gene is present in approximately $25 \%$ of childhood B-ALL patients and represents the molecular equivalent of the $t(12 ; 21)$ translocation (Romana et al., 1995). Down-regulation of the endogenous ETV6/RUNX1 fusion protein with shRNA in $B-A L L$ cell lines resulted in suppression of cytokine-mediated $\mathrm{PI3K} / \mathrm{Akt} / \mathrm{mTOR}$ signaling. However, no mechanistic explanation of how ETV6/RUNX1 protein could impact on PI3K/Akt/mTOR cascade was provided by the authors (Fuka et al., 2012).

As to PTEN, it has been demonstrated that adult $\mathrm{Ph}^{-}$and $\mathrm{Ph}^{+}$both B-ALL primary samples displayed decreased PTEN activity and constitutive hyperactivation of $\mathrm{PI} 3 \mathrm{~K} / \mathrm{Akt} / \mathrm{mTOR}$ pathway despite high PTEN protein levels (Gomes et al., 2014). PTEN functional inactivation was dependent on CK2 that targets several Ser/Thr residues located at the $\mathrm{C}$-terminal tail of PTEN (Buontempo et al., 2018). Indeed, treatment of B-ALL primary cells and cell lines with the CK2 inhibitor CX-4945 resulted in decreased PTEN phosphorylation, downregulation of PTEN protein expression, increased PTEN lipid phosphatase activity, and Akt dephosphorylation. These results indicated that CK2 activity could be responsible for PTEN posttranslational inactivation and upregulation of the PI3K/Akt/mTOR network in B-ALL cells (Gomes et al., 2014).

Overall, these findings have documented that multiple mechanisms could be involved in activation of PI3K/Akt/mTOR signaling in $\mathrm{Ph}^{-} \mathrm{B}-\mathrm{ALL}$ (Figure 1b).

As to Ph-like B-ALL, aberrant PI3K/Akt/mTOR signaling has been reported in this disease subset which frequently displays a wide array of genetic anomalies which result in upregulation of signaling pathways downstream of LNK/SH2B3, CLRF2, JAK 1/2, IL-7Ra, Abl 1/2, platelet-derived growth factor receptor- $\beta$ (PDGFRB), colony-stimulating factor-1 receptor (CSF1R), and erythropoietin receptor (EPOR) (Cheng et al., 2016; Reshmi et al., 2017). All of these aberrations have the potential for driving PI3K/ Akt/mTOR signaling (Maude et al., 2012; Tasian et al., 2017; Vo et al., 2017) (Figure 1c).

\section{4 | THERAPEUTIC TARGETING OF PI3K/Akt/mTOR IN PRECLINICAL MODELS OF B-ALL}

Many small molecules targeting different nodes of the PI3K/Akt/ mTOR signaling cascades have been or are in clinical development, however it is still unclear which of the different drugs could provide the greatest therapeutic index (Rodon \& Tabernero, 2017). We will now review the different classes of inhibitors which have been tested in preclinical models of B-ALL subtypes (Table 1 and Figure 2).

\section{5 | PI3K INHIBITORS}

PI3K inhibitors comprise pan p110 PI3K inhibitors and isoformspecific inhibitors. The first report showing that a pan p110 PI3K inhibitor (LY294002) could induce either cell cycle arrest or apoptosis in a $\mathrm{Ph}^{-} \mathrm{B}-\mathrm{ALL}$ cell line, RS4;t11, dates back to 2004 when it was observed that Akt activation was required for the protective effects exerted by human stromal cells on B-ALL cells exposed to chemotherapeutic drugs such as Ara-C and etoposide (Wang, Fortney, \& Gibson, 2004). These results were confirmed by another group which demonstrated, using BLIN-2 B-ALL cells, that either LY294002 or rapamycin, were proapoptotic only when combined with U0126, a MEK inhibitor. In contrast, when these drugs were combined with a JAK2 inhibitor (AG490) they were cytostatic, as they blocked cell proliferation, even when leukemic cells were co-cultured with stromal cells (Bertrand, Spengemen, Shelton, \& McCubrey, 2005). However, LY294002 has not been clinically developed, mainly due to solubility problems.

The clinical grade pan p110 PI3K inhibitor BKM-120 (Buparlisib) has been tested in long-term cultures of primary $\mathrm{Ph}^{+}$and $\mathrm{Ph}^{-} \mathrm{B}-\mathrm{ALL}$ cells (Badura et al., 2013). BKM-120 induced both cell cycle arrest and apoptosis. Nevertheless, its antiproliferative effects were more evident in $\mathrm{Ph}^{-}$cells when compared to $\mathrm{Ph}^{+}$cells, whereas apoptosis induction was stronger in $\mathrm{Ph}^{+}$samples. More recently, the proapoptotic activity of BKM-120 in $\mathrm{Ph}^{-}$NALM-6 B-ALL cells was linked to upregulation of p53-regulated genes (Bashash et al., 2016).

Selective inhibitors, targeting one or two of the p110 PI3K catalytic subunits, have been synthesized with the hope that they would result in lower systemic toxicities than pan p110PI3K inhibitors (Hirsch \& Chiarle, 2012). In consideration of the high levels of expression of p1108 PI3K in healthy lymphocytes (Chiu et al., 2017), inhibitors selectivity targeting this p110 PI3K isoform have been tested in preclinical models of $\mathrm{Ph}^{-} \mathrm{B}-\mathrm{ALL}$. CAL-101 (Idelalisib) is a p1108 PI3K inhibitor whose use has been approved by the U.S. Food and Drug Administration (FDA) in combination with rituximab, an antiCD20 antibody, as a second-line treatment for relapsed chronic lymphocytic leukemia (CLL) patients (Jones et al., 2017).

CAL-101 exerted cytotoxic effects against Nalm-6 B-ALL cells mediated by $G_{1}$ blockage (presumably as a result of upregulated $p 21$ ) and induction of caspase-dependent apoptosis, likely through reactive oxygen species-dependent upregulation of FOXO3a and subsequent induction of the proapoptotic target genes of p53 (Safaroghli-Azar, Bashash, Sadreazami, Momeny, \& Ghaffari, 2017). Furthermore, CAL101 increased the cytotoxicity of either doxorubicin (Safaroghli-Azar et al., 2017) or vincristine (Adam et al., 2017). Importantly, CAL-101 was able to decrease Akt phosphorylation at Ser 473 which was increased when B-ALL cell lines were co-cultured with OP-9 stromal cells (Adam et al., 2017). Furthermore, CAL-101 inhibited B-ALL cell migration to CXCL-12 (SDF-1a) in vitro and blocked homing of B-ALL cells to the bone marrow in vivo. It was thus concluded that inhibition of homing of circulating B-ALL cells to the bone marrow or even mobilization of leukemic cells from their protective niches in the bone marrow might interfere with cell adhesion-mediated drug-resistance 
TABLE $1 \mathrm{PISK/AKT/mTOR} \mathrm{inhibitors} \mathrm{used} \mathrm{alone} \mathrm{or} \mathrm{in} \mathrm{combination} \mathrm{in} \mathrm{preclinical} \mathrm{models} \mathrm{of} \mathrm{B-ALL}$

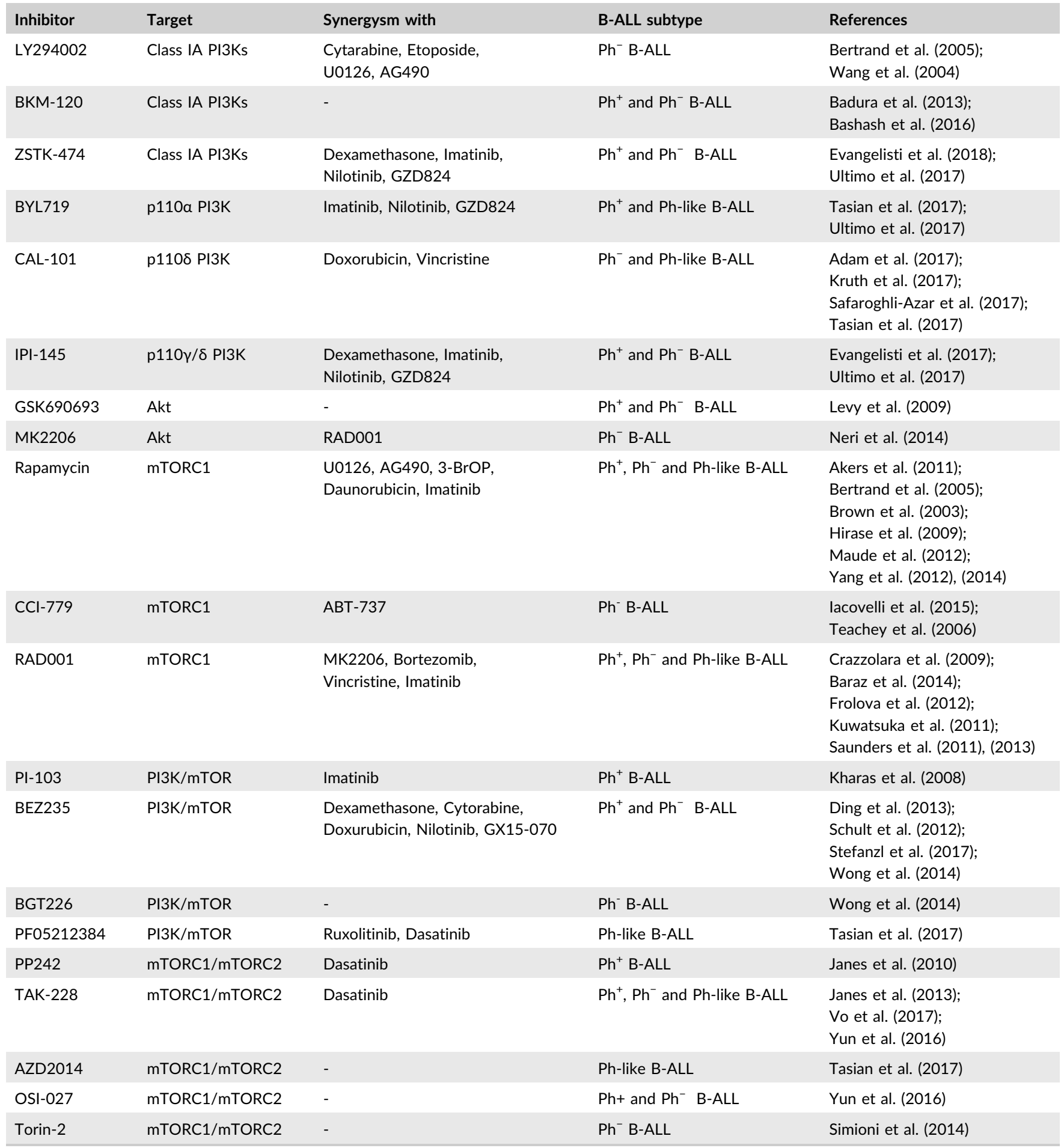

(Adam et al., 2017). Overall, these findings support the rationale for clinical testing of p1108 PI3K inhibitors in B-ALL and provide useful insights needed to optimize the therapeutic strategy.

Glucocorticoids (GCs) are widely used in chemotherapeutic protocols for B-ALL, due to their strong proapoptotic activity to leukemic cells. It was recently disclosed that dexamethasone (DEX) partially suppresses the PI3K/Akt signaling cascade in B-ALL cells. This results in nuclear translocation of the Akt substrate FOXO3a, which induces the expression of downstream targets, including p27Kip1 and Bim (Consolaro et al., 2015). We have recently studied the therapeutic potential of a panel of pan and isoform-selective p110 PI3K inhibitors, used alone or combined with DEX, in B-ALL leukemia cell lines and primary pediatric samples. We found that ZSTK-474, a pan p110 PI3K inhibitor, displayed the most powerful cytotoxic effects in B-ALL cells. However, both ZSTK-474 and the dual $\gamma / \delta$ p110 PI3K inhibitor IPI-145 (Duvelisib), sensitized B-ALL cells to DEX by restoring nuclear 


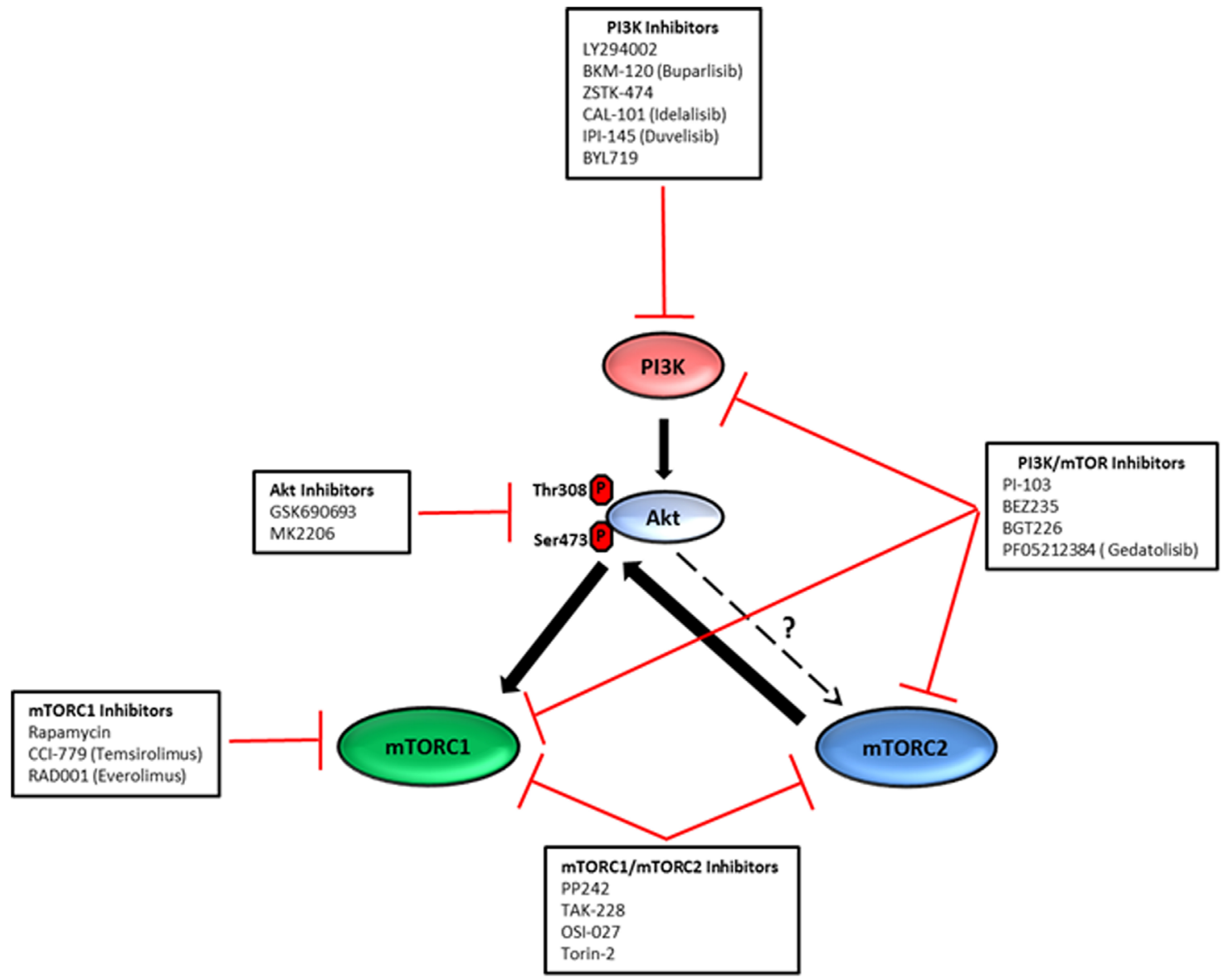

FIGURE 2 Small molecule inhibitors used for targeting the key nodes of the PI3K/Akt/mTOR cascade in preclinical models of B-ALL. For the details, see the text

translocation of the GC receptor and counteracted stromal cellinduced DEX-resistance (Evangelisti et al., 2018). Moreover, we performed gene expression analysis which demonstrated that the combination consisting of ZSTK-474 and DEX strengthened the DEXinduced up- or downregulation of several genes involved in apoptosis, however the combination also rescued the effects of genes that might be involved in GC-resistance. Another group has recently demonstrated that CAL-101 synergizes with DEX in $\mathrm{Ph}^{-} \mathrm{B}-\mathrm{ALL}$ cell lines and primary samples from DEX-resistant patients (Kruth et al., 2017).

It has been proposed that PI3K/Akt/mTOR signaling is involved in the resistance of $\mathrm{Ph}^{+} \mathrm{B}$-ALL cells to the TKI, imatinib (Guo et al., 2017; Xing et al., 2012; Wang et al., 2014). For this reason, our group has recently investigated the therapeutic potential of combining $\mathrm{PI} 3 \mathrm{~K}$ inhibitors with TKIs in the $\mathrm{Ph}^{+} \mathrm{B}-\mathrm{ALL}$ cell line SUP-B15. We used the pan p110 PI3K inhibitor ZSTK-474, the p110a PI3K inhibitor BYL719 and the dual $\gamma / \delta$ p110 PI3K inhibitor IPI-145. As to TKIs, we employed imatinib, the second generation Bcr-Abl inhibitor nilotinib and the third generation orally bioavailable TKI, GZD824 (Ultimo et al., 2017). Of note, GZD824 is effective against a wide range of Bcr-Abl mutants, including T315I (Ren et al., 2013). We observed synergistic cytotoxic effects with the various combinations which were due to apoptosis induction. However, the combined treatments also induced autophagy, which might have a protective effect (Ultimo et al., 2017). In this connection, it is important to emphasize how an ATPcompetitive dual inhibitor of PI3K p1108/Vps34, PI3KD/V-IN-01, exhibited better antiproliferative activity against cell lines representative of B-cell malignancies than known selective PI3K p1108 and Vps34 inhibitors (Liu et al., 2016). PI3KD/V-IN-01 has not been tested in B-ALL preclinical settings, however, its use should be considered in light of our own findings (Ultimo et al., 2017).

Overall, all of the above highlighted results support the rationale for clinical testing of either pan p110 or isoform-selective PI3K inhibitors in B-ALL patients, especially in combination with traditional chemotherapeutic drugs or TKIs, and provide useful insights needed to optimize the therapeutic strategy, including the protective role played by autophagy when leukemic cells are treated with PI3K inhibitors.

\section{1 | Akt inhibitors}

Historically, Akt has been a difficult target to inhibit with ATPcompetitive small molecules. Indeed, the ATP-binding pocket of Akt shares many homologies with other members of the AGC kinase family (Pearce, Komander, \& Alessi, 2010). GSK690693 is an ATP-competitive inhibitor which targets Akt (Rhodes et al., 2008). GSK690693 has 
been tested in $\mathrm{Ph}^{+}$and $\mathrm{Ph}^{-} \mathrm{B}-\mathrm{ALL}$ cell lines where it induced a cell proliferation block and apoptosis accompanied by a dephosphorylation of Akt downstream targets, including GSK3 $\beta$, PRAS40, and p70S6K (Levy, Kahana, \& Kumar, 2009). Importantly, both stimulated peripheral blood $\mathrm{CD}^{+}$T-cells from healthy donors and mouse thymocytes were less sensitive to GSK690693 than leukemic cells. Nevertheless, dose-limiting toxicities that are likely on target, associated with hyperglycemia, led to termination of the clinical development of this drug (Manning \& Toker, 2017). MK2206 is a specific, potent, and orally bioavailable allosteric inhibitor that targets both the catalytic and the PH domains of Akt (Hirai et al., 2010). We have shown that MK2206 strongly synergized with the mTORC1 inhibitor, RAD001, in both $\mathrm{Ph}^{-} \mathrm{B}-\mathrm{ALL}$ cell lines and patient samples (Neri et al., 2014). Our findings could have important implications, as MK2206 has not shown significant efficacy in the clinic as single agent therapy in patients with acute myelogenous leukemia (Konopleva et al., 2014). However, its effects could be conceivably enhanced by other drugs used in combination therapy.

\section{2 | Allosteric mTOR inhibitors}

Allosteric mTOR inhibitors (rapamycin, $\mathrm{CCl}$-779, RAD001) have been widely used in preclinical models of B-ALL. For example, rapamycin negatively affected in vitro the growth of $E \mu$-ret transgenic mousederived cell lines as well as that of $\mathrm{Ph}^{-}$human $\mathrm{B}-\mathrm{ALL}$ cell lines (NALM6, NALM-16). Moreover, rapamycin induced apoptosis in the murine pro-B ALL cell line T309 (Brown et al., 2003). Interestingly, the inhibitory effects of rapamycin could be reversed by IL-7, which suggests an important role of this cytokine in the control of mTOR activity in B-ALL cells. Rapamycin was also effective in vivo, as it extended survival in E $\mu$-ret transgenic mice with advanced B-ALL compared with control littermates (Brown et al., 2003).

In vitro, $\mathrm{CCl}-779$ (Temsirolimus) dramatically decreased survival and increased apoptosis of lymphoblasts from $\mathrm{Ph}^{-} \mathrm{B}-\mathrm{ALL}$ adult patients co-cultured with bone marrow stromal cells. The drug was also effective in vivo in a NOD/SCID xenograft model (Teachey et al., 2006). Recently, $\mathrm{CCl}-779$ has been shown to synergize with the $\mathrm{Bcl}-2$ inhibitor, ABT-737, in ABT-737-resistant pediatric and adult $\mathrm{Ph}^{-} \mathrm{B}$ ALL cells, by downregulating mTORC1 activity and Mcl-1 (lacovelli et al., 2015).

Also RAD001 has proven its efficacy, especially in models of $\mathrm{Ph}^{-}$ pediatric B-ALL. Importantly, RAD001 synergized with conventional chemotherapy (e.g., vincristine) or novel agents (e.g., bortezomib) both in vitro and in vivo, with increased caspase-dependent, but p53independent, cell killing (Saunders, Cisterne, Weiss, Bradstock, \& Bendall, 2011; Saunders et al., 2013). However, it has also been shown that RAD001 induces other types of cell death, including autophagy (Crazzolara, Bradstock, \& Bendall, 2009) and caspase-independent paraptosis (Baraz et al., 2014).

It should be considered that interactions between leukemic cells and the bone marrow microenvironment promote B-ALL cell survival and confer resistance to chemotherapy (Chiarini et al., 2016). Hypoxia is an integral component of bone marrow microenvironment (Petit et al., 2016). Hypoxia-inducible factor-1a (HIF-1a) plays key roles in response to hypoxia by regulating leukemic cell growth and metabolic adaptation to hypoxia, as well as drug-resistance (Deynoux, Sunter, Herault, \& Mazurier, 2016). Remarkably, mTOR blockade with RAD001 reduced HIF-1a expression, diminished glucose uptake and glycolytic rate, and partially restored the chemosensitivity of B-ALL cells co-cultured with bone marrow stromal cells under hypoxic conditions (Frolova et al., 2012).

In this connection it is important to emphasize that cancer cells, including acute leukemia cells, show the propensity to metabolize glucose to lactate for ATP production even under aerobic conditions, the so-called "Warburg effect" (Kalyanaraman, 2017). Therefore, drugs targeting glycolysis are now being studied for developing innovative anticancer therapies (Granja, Pinheiro, Reis, Martinho, \& Baltazar, 2015). mTORC1 senses metabolic stresses, such as lowered glucose metabolite levels, and ATP concentrations, and compensates for these stresses, allowing cells to become resistant to glycolysis inhibition (Jellusova \& Rickert, 2016). Interestingly, rapamycin potentiated the effects of the novel, third-generation glycolysis inhibitor, 3-bromo-2oxopropionate-1-propyl ester (3-BrOP), a cell permeable ester of 3bromopyruvate (3-BrPA) (Lis et al., 2016). NALM-6 B-ALL cells treated with 3-BrOP and rapamycin displayed a decrease in viability compared to either agent alone (Akers et al., 2011). These findings suggest that when ATP is depleted by glycolysis inhibition, simultaneous targeting of mTORC1 may further limit nutrient uptake, ensuing in stronger cytotoxic effects.

Rapamycin has shown efficacy in preclinical models of xenografted pediatric Ph-like B-ALL with and without CRLF2 and JAK genetic lesions. Indeed, the drug controlled leukemia burden in all eight B-ALL samples analyzed, while a prolonged survival was observed in two representative xenografts treated with rapamycin when compared with vehicle (Maude et al., 2012).

As to $\mathrm{Ph}^{+} \mathrm{B}-\mathrm{ALL}$, it has been shown that rapamycin was cytotoxic not only for the Bcr-Abl ${ }^{+}$leukemic lymphoid cell line, SU-Ph2, but also for the imatinib-resistant cell line, SU/SR, that has acquired the T315I mutation (Hirase, Maeda, Takai, \& Kanamaru, 2009). Moreover, rapamycin potentiated the effects of imatinib in SUP-B15 $\mathrm{Ph}^{+} \mathrm{B}-$ ALL cells and primary samples from patients when combined with daunorubicin (Yang et al., 2012). Remarkably, it was reported that daunorubicin treatment up-regulated mTORC1 signaling, whereas rapamycin effectively counteracted such a deleterious side effect, which might dampen daunorubicin ability to kill leukemic cells. The same group subsequently reported that imatinib enhanced mTORC1 signaling, therefore its association with rapamycin increased imatinib cytotoxicity in SUP-B15 cells (Yang et al., 2014).

Importantly, it has also been shown that RAD001 overcame resistance to imatinib by targeting in vitro and in vivo a mostly quiescent $\mathrm{Ph}^{+} \mathrm{B}-\mathrm{ALL}$ cell subset (CD34 ${ }^{+} / \mathrm{CD} 38^{-}$) (Kuwatsuka et al., 2011). It is well known that this cell subset is enriched in leukemic stem cells (LSCs) that are intrinsically resistant to TKIs, probably, although not exclusively, due to their quiescence (Graham et al., 2002).

The RAD001/imatinib combined treatment induced in vitro apoptosis of $\mathrm{CD} 34^{+} / \mathrm{CD}^{-} 8^{-}$cells more efficiently than RAD001 alone 
(Kuwatsuka et al., 2011). These findings imply that co-treatment with RAD001 can overcome resistance to imatinib in $\mathrm{Ph}^{+} \mathrm{B}-\mathrm{ALL}$ LSCs and may pave the way for more effective treatments aimed to lower the percentage of patients who relapse after TKI treatment.

Together, all these preclinical observations suggest that allosteric mTOR inhibitors, especially when combined with conventional chemotherapy or novel targeted agents, have the potential to improve clinical responses in patients with different types of B-ALL, including high risk $\mathrm{Ph}^{+}$and $\mathrm{Ph}$-like cases.

\section{3 | Dual PI3K/mTOR inhibitors}

Since both PI3K and mTOR belong to the PIKK superfamily of kinases, they share high sequence homology in their catalytic domains. Dual $\mathrm{PI} 3 \mathrm{~K} / \mathrm{mTOR}$ inhibitors were originally developed as PI3K inhibitors, but were subsequently shown to also effectively inhibit both mTORC1 and mTORC2 (Chiarini, Evangelisti, McCubrey, \& Martelli, 2015). The use of this class of drugs should blunt mTORC2-dependent activation of Akt effected through PI3K (Janes et al., 2010).

PI-103, BEZ235, BTG226, and PF05212384 (Gedatolisib) are dual $\mathrm{PI} 3 \mathrm{~K} / \mathrm{mTOR}$ inhibitors that have been employed in preclinical models of B-ALL.

$\mathrm{PI}-103$ was more efficacious than rapamycin at suppressing proliferation of murine and human $\mathrm{Ph}^{+} \mathrm{B}-\mathrm{ALL}$ leukemia cells treated with the TKI inhibitor, imatinib (Kharas et al., 2008). BEZ235 displayed cytotoxic effects in both $\mathrm{Ph}^{-}$(Schult et al., 2012; Wong, Welschinger, Hewson, Bradstock, \& Bendall, 2014) and $\mathrm{Ph}^{+} \mathrm{B}-\mathrm{ALL}$ cells (Ding et al., 2013), while BTG226 has been tested only in $\mathrm{Ph}^{-}$models, where it was more powerful than BEZ235 (Wong et al., 2014). Both drugs, however, inhibited the proliferation of $\mathrm{Ph}^{-} \mathrm{B}-\mathrm{ALL}$ cell lines with a three log greater potency than RAD001 (Wong et al., 2014). BEZ235 synergized with traditional chemotherapeutic drugs, including cytarabine, doxorubicin, and DEX in $\mathrm{Ph}^{-} \mathrm{B}-\mathrm{ALL}$ cells (Schult et al., 2012), while the inhibitor was synergistic with the second-generation TKI, nilotinib, in $\mathrm{Ph}^{+}$SUP-B15 cells. Interestingly, nilotinib, when administered alone, upregulated PI3K/Akt/mTOR signaling (Ding et al., 2013). Moreover, $\mathrm{BEZ235}$ has been recently shown to synergize with the $\mathrm{Bcl}-2$ inhibitor, GX15-070 (Obatoclax ${ }^{@}$ ), in $\mathrm{Ph}^{+}$and $\mathrm{Ph}^{-}$primary B-ALL cells and cell lines (Stefanzl et al., 2017).

While the clinical development of BEZ235 and BTG226 has been halted, that of PF05212384 is being continued (Rodon \& Tabernero, 2017). Remarkably, PF05212384 displayed anticancer activity in childhood B-ALL patient-derived xenograft models harboring various Ph-like genomic alterations (Tasian et al., 2017). PF05212384 was particularly effective in CRLF2/JAK-mutant models with a mean 92.2\% leukemia proliferation reduction versus vehicle controls and significantly prolonged mice survival. It displayed a lower efficacy in Abl/PDGFR-mutant models. Overall, PF05212384 was more potent than the p110a PI3K inhibitor BYL719, the p1108 PI3K inhibitor CAL-101, or the mTORC1/mTORC2 inhibitor AZD2014. Nevertheless, the efficacy of PF05212384 monotehrapy was enhanced by combining the $\mathrm{PI} 3 \mathrm{~K} / \mathrm{mTOR}$ inhibitor with either a JAK inhibitor (Ruxolitinib) in CRLF2/JAK-mutant models or the TKI dasatinib in
Abl/PDGFR-mutant models (Tasian et al., 2017). These data suggested that $\mathrm{Ph}$-like $\mathrm{B}-\mathrm{ALL}$ requires $\mathrm{PI} 3 \mathrm{~K} / \mathrm{Akt} / \mathrm{mTOR}$ pathway activation for survival in vivo. Moreover, they indicated that clinical trials testing combinations of kinase inhibitors in Ph-like B-ALL patients are warranted.

\section{6 | ATP-COMPETITIVE mTORC1/mTORC2 INHIBITORS}

This class of drugs, that target both mTOR complexes but not PI3K, was designed to reduce toxicity due to the use of dual PI3K/mTOR inhibitors (Pal \& Quinn, 2013). Moreover, these inhibitors can potentially prevent the feedback loop activation of Akt caused by rapamycin/rapalogs in B-ALL cells (Badura et al., 2013). In analogy with dual PI3K/mTOR inhibitors, the ATP-competitive mTORC1/mTORC2 inhibitor PP242, displayed more powerful cytotoxic effects as well as a more complete inhibition of mTORC1 outputs compared with rapamycin in preclinical models of murine and human $\mathrm{Ph}^{+} \mathrm{B}-\mathrm{ALL}$ cells (Janes et al., 2010).

TAK-228 (formerly known as INK128/MLN0128) is an orally active $\mathrm{mTORC} 1 / \mathrm{mTORC} 2$ inhibitor currently in clinical development. TAK-228 suppressed proliferation of B-ALL cell lines in vitro and reduced colony formation by primary human leukemia cells from both adult and pediatric $\mathrm{Ph}^{-} \mathrm{B}-\mathrm{ALL}$ patients. TAK-228 also increased the efficacy of dasatinib in $\mathrm{Ph}^{+}$primary samples (Janes et al., 2013). This inhibitor was also effective in various in vivo models of B-ALL, including a syngeneic mice model of lymphoid $\mathrm{Ph}^{+}$disease, and primary xenografts of either $\mathrm{Ph}^{+}$or $\mathrm{Ph}^{-}$human $\mathrm{B}-\mathrm{ALL}$ samples, Remarkably, in all the in vivo models, TAK-228 was well tolerated and did not suppress endogenous bone marrow proliferation (Janes et al., 2013). Very recently, however, it has been shown that inhibiting mTORC1 with TAK-228 protected $\mathrm{Ph}^{+}$and $\mathrm{Ph}$-like B-ALL cells from killing by methotrexate and 6-mercaptopurine, two drugs used in maintenance chemotherapy. These cytoprotective effects of TAK-228 correlated with decreased cell-cycle progression and were also detected with cell-cycle inhibitors, such as palbociclib or aphidicolin (Vo et al., 2017). Using xenograft models, it was observed that mTOR inhibition by TAK228 actually increased the number of leukemia cells that emerged after cessation of chemotherapy treatment.

Interestingly, the use of TAK-228 and shRNA-mediated downregulation of either Raptor or Rictor allowed the identification of two previoulsy unrecognized mTOR-dependent pathways critical for $\mathrm{Ph}^{+}$ and $\mathrm{Ph}^{-}$B-ALL cell survival. Inhibition of mTORC1-mediated 4E-BP1 phosphorylation led to decreased expression of c-Myc and subsequent upregulation of the proapoptotic Bcl-2 family member PUMA, whereas inhibition of mTORC2 resulted in NF-kB-mediated expression of the Early Growth Response 1 (EGR1) gene, that encodes a transcription factor which binds and transactivates the proapoptotic BCL2L11 gene encoding Bim protein (Yun et al., 2016). Importantly, 1 or both pathways contributed to apoptosis of malignant B-ALL cells after treatment with the dual mTORC1/mTORC2 inhibitors, OSI-027 and TAK-228. 
Our group has documented that the ATP-competitive mTORC1/ mTORC2 inhibitor, Torin-2, was cytotoxic to a panel of $\mathrm{Ph}^{-} \mathrm{B}-\mathrm{ALL}$ cell lines and indeed suppressed the rapalog-dependent feedback activation of Akt, whereas RAD001 required the addition of the Akt inhibitor MK-2206 to achieve the same effects (Simioni et al., 2014).

Overall, these findings support the rationale for clinical testing of ATP-competitive mTORC1/mTORC2 inhibitors in both $\mathrm{Ph}^{+}$and $\mathrm{Ph}^{-} \mathrm{B}$ ALL patients. However, they also highlight that inhibitors targeting mTOR should be used with caution in combination with chemotherapeutic drugs that rely on cell-cycle progression to kill leukemic cells.

\section{7 | CONCLUSIONS AND FUTURE DIRECTIONS}

The evidence reviewed here documents that PI3K/Akt/mTORgenerated signals play central roles in the control of B-ALL cell proliferation, survival, metabolism, and drug-resistance, making this signal transduction cascade an attractive target for antileukemic therapy. These findings have highlighted PI3K/Akt/mTOR inhibitors as molecules to be possibly tested in clinical trials aimed to treat B-ALL patients, although several fundamental outstanding issues still need to be addressed.

In particular, will inhibition of $\mathrm{PI} 3 \mathrm{~K} / \mathrm{Akt} / \mathrm{mTOR}$ signaling negatively affect leukemic cells without deleterious side effects on healthy cells? In other words, is there a therapeutic window when such a ubiquitous signal transduction cascade is to be targeted? While the discovery of $\mathrm{PI} 3 \mathrm{~K} / \mathrm{Akt} / \mathrm{mTOR}$ inhibitors yielded a flood of promising and exciting preclinical data, the initial wave of clinical trials based on these drugs has not resulted in widespread and durable patient responses. These trials have demonstrated that $\mathrm{PI} 3 \mathrm{~K} / \mathrm{Akt} / \mathrm{mTOR}$ pathway inhibitors frquently displayed significant on- and off-target toxicities that were dose-limiting, often leading to the use of subtherapeutic maximum tolerated doses, which resulted in insufficient pathway inhibition. Rapamycin/rapalogs were generally quite well tolerated, however they have shown a modest anticancer activity when used alone. This low efficacy is usually explained by the feedback activation of Akt, as we have discussed in this review.

As a consequence of these trials, only a handful of these inhibitors have been approved for clinical use as anticancer agents in the U.S. and Europe (Chiarini et al., 2015; Rodon \& Tabernero, 2017). The depth and duration of target inhibition as well as safety profiles of these compounds may be improved through the use of intermittent dosing schedules, which could lead to a better drug exposure with more effective target inhibition and fewer off-target adverse effects, as seen in other types of cancer (Guichard et al., 2015; Tolcher et al., 2015; Yates, Dudley, Cheng, D'Cruz, \& Davies, 2015).

Furthermore, preclinical data strongly suggest that identifying combinations, either with targeted agents or with chemotherapy, might be the key to unleashing the full potential of PI3K/Akt/mTOR inhibitors in B-ALL patients, as we have highlighted in this review. Early clinical data support this claim in other cancer types (Andre et al., 2014; Moscetti et al., 2016), although it will have to be conclusively demonstrated that improved clinical responses will not be accompanied by unacceptable toxicities (Baselga et al., 2017).

Another critical issue will be the identification of biomarkers that could accurately predict PI3K/Akt/mTOR pathway inhibitor efficacy in B-ALL patients. In this connection, techniques such as kinase activity profiling and computational analysis could give a deeper insight in active signal transduction pathways and point out critical signaling hubs as well as new potential druggable targets or resistant patients, as recently demonstrated also in B-ALL cells (Casado et al., 2013; van der Sligte et al., 2015).

We also need to better understand the effects of the pathway inhibitors on the immunosuppressive leukemic microenvironment. Indeed, recent evidence pointed out that B-ALL cells induced inhibition of T-cell Akt/mTORC1 signaling and glucose metabolism that drove Tcell function impairment, while an enforced Akt/mTORC1 signaling rescued $\mathrm{T}$-cell metabolism and partially improved anti-leukemia immunity (Siska et al., 2016). Therefore, the use of PI3K/Akt/mTOR inhibitors could further blunt immunological responses against leukemic cells.

In conclusion, the field of PI3K/Akt/mTOR targeted therapies has progressed very rapidly over the past 15 years and, as our knowledge of the biology continuously increases, so too will our capacity to improve and finely tune these novel therapies to positively affect BALL patient outcome.

\section{CONFLICTS OF INTEREST}

None declared.

\section{ORCID}

Luca M. Neri (iD http://orcid.org/0000-0002-7924-1477

\section{REFERENCES}

Adam, E., Kim, H. N., Gang, E. J., Schnair, C., Lee, S., Lee, S., .. Kim, Y. M. (2017). The PI3Kð inhibitor idelalisib inhibits homing in an in vitro and in vivo model of B ALL. Cancers, 9, E121.

Akers, L. J., Fang, W., Levy, A. G., Franklin, A. R., Huang, P., \& ZweidlerMcKay, P. A. (2011). Targeting glycolysis in leukemia: A novel inhibitor 3-BrOP in combination with rapamycin. Leukemia Research, 35, 814-820.

Alayev, A., \& Holz, M. K. (2013). mTOR signaling for biological control and cancer. Journal of Cellular Physiology, 228, 1658-1664.

Alayev, A., Salamon, R. S., Schwartz, N. S., Berman, A. Y., Wiener, S. L., \& Holz, M. K. (2017). Combination of rapamycin and resveratrol for treatment of bladder cancer. Journal of Cellular Physiology, 232, 436-446.

Andre, F., O'Regan, R., Ozguroglu, M., Toi, M., Xu, B., Jerusalem, G., ... Gianni, L. (2014). Everolimus for women with trastuzumab-resistant, HER2-positive, advanced breast cancer (BOLERO-3): a randomised, double-blind, placebo-controlled phase 3 trial. Lancet Oncology, 15, 580-591.

Badura, S., Tesanovic, T., Pfeifer, H., Wystub, S., Nijmeijer, B. A., Liebermann, M., ... Ottmann, O. G. (2013). Differential effects of 
selective inhibitors targeting the $\mathrm{PI} 3 \mathrm{~K} / \mathrm{AKT} / \mathrm{mTOR}$ pathway in acute lymphoblastic leukemia. PLoS ONE, 8, e80070.

Bahrami, A., Khazaei, M., Shahidsales, S., Hassanian, S. M., Hasanzadeh, M., Maftouh, M., ... Avan, A. (2018). The therapeutic potential of PI3K/ Akt/mTOR Inhibitors in breast cancer: Rational and progress. Journal of Cellular Biochemistry, 119, 213-222.

Baraz, R., Cisterne, A., Saunders, P. O., Hewson, J., Thien, M., Weiss, J., ... Bendall, L. J. (2014). mTOR inhibition by everolimus in childhood acute lymphoblastic leukemia induces caspase-independent cell death. PLoS ONE, 9, e102494.

Baselga, J., Im, S. A., Iwata, H., Cortes, J., De Laurentiis, M., Jiang, Z., ... Campone, M. (2017). Buparlisib plus fulvestrant versus placebo plus fulvestrant in postmenopausal, hormone receptor-positive, HER2negative, advanced breast cancer (BELLE-2): A randomised, doubleblind, placebo-controlled, phase 3 trial. Lancet Oncology, 18, 904-916.

Bashash, D., Safaroghli-Azar, A., Delshad, M., Bayati, S., Nooshinfar, E., \& Ghaffari, S. H. (2016). Inhibitor of pan class-I PI3K induces differentially apoptotic pathways in acute leukemia cells: Shedding new light on NVPBKM120 mechanism of action. International Journal of Biochemistry \& Cell Biology, 79, 308-317.

Bertacchini, J., Guida, M., Accordi, B., Mediani, L., Martelli, A. M., Barozzi, P., ... Marmiroli, S. (2014). Feedbacks and adaptive capabilities of the $\mathrm{PI} 3 \mathrm{~K} / \mathrm{Akt} / \mathrm{mTOR}$ axis in acute myeloid leukemia revealed by pathway selective inhibition and phosphoproteome analysis. Leukemia, 28, 2197-2205.

Bertacchini, J., Heidari, N., Mediani, L., Capitani, S., Shahjahani, M., Ahmadzadeh, A., \& Saki, N. (2015). Targeting PI3K/AKT/mTOR network for treatment of leukemia. Cellular and Molecular Life Sciences, 72, 2337-2347.

Bertrand, F. E., Spengemen, J. D., Shelton, J. G., \& McCubrey, J. A. (2005). Inhibition of PI3K, mTOR and MEK signaling pathways promotes rapid apoptosis in B-lineage ALL in the presence of stromal cell support. Leukemia, 19, 98-102.

Bhaskar, P. T., \& Hay, N. (2007). The two TORCs and Akt. Developmental Cell, 12, 487-502.

Brehme, M., Hantschel, O., Colinge, J., Kaupe, I., Planyavsky, M., Kocher, T., ... Superti-Furga, G. (2009). Charting the molecular network of the drug target Bcr-Abl. Proceedings of the National Academy of Sciences of the United States of America, 106, 7414-7419.

Brown, V. I., Fang, J., Alcorn, K., Barr, R., Kim, J. M., Wasserman, R., \& Grupp, S. A. (2003). Rapamycin is active against B-precursor leukemia in vitro and in vivo, an effect that is modulated by IL-7-mediated signaling. Proceedings of the National Academy of Sciences of the United States of America, 100, 15113-15118.

Brown, V. I., Hulitt, J., Fish, J., Sheen, C., Bruno, M., Xu, Q., ... Grupp, S. A. (2007). Thymic stromal-derived lymphopoietin induces proliferation of pre-B leukemia and antagonizes mTOR inhibitors, suggesting a role for interleukin-7Ra signaling. Cancer Research, 67, 9963-9970.

Browne, G. J., \& Proud, C. G. (2004). A novel mTOR-regulated phosphorylation site in elongation factor 2 kinase modulates the activity of the kinase and its binding to calmodulin. Molecular and Cellular Biology, 24, 2986-2997.

Buontempo, F., McCubrey, J. A., Orsini, E., Ruzzene, M., Cappellini, A., Lonetti, A., ... Martelli, A. M. (2018). Therapeutic targeting of CK2 in acute and chronic leukemias. Leukemia, 32, 1-10.

Cantley, L. C. (2002). The phosphoinositide 3-kinase pathway. Science, 296 1655-1657.

Casado, P., Rodriguez-Prados, J. C., Cosulich, S. C., Guichard, S., Vanhaesebroeck, B., Joel, S., \& Cutillas, P. R. (2013). Kinase-substrate enrichment analysis provides insights into the heterogeneity of signaling pathway activation in leukemia cells. Science Signaling, 6, rs6.

Chen, S., Rehman, S. K., Zhang, W., Wen, A., Yao, L., \& Zhang, J. (2010). Autophagy is a therapeutic target in anticancer drug resistance. Biochimica et Biophysica Acta, 1806, 220-229.
Cheng, Y., Chikwava, K., Wu, C., Zhang, H., Bhagat, A., Pei, D., .. Tong, W. (2016). LNK/SH2B3 regulates IL-7 receptor signaling in normal and malignant B-progenitors. Journal of Clinical Investigation, 126, 1267-1281.

Chiarini, F., Evangelisti, C., McCubrey, J. A., \& Martelli, A. M. (2015). Current treatment strategies for inhibiting mTOR in cancer. Trends in Pharmacological Sciences, 36, 124-135.

Chiarini, F., Lonetti, A., Evangelisti, C., Buontempo, F., Orsini, E., Evangelisti, C., ... Martelli, A. M. (2016). Advances in understanding the acute lymphoblastic leukemia bone marrow microenvironment: From biology to therapeutic targeting. Biochimica et Biophysica Acta, 1863, 449-463.

Chiu, H., Mallya, S., Nguyen, P., Mai, A., Jackson, L. V., Winkler, D. G., .. Fruman, D. A. (2017). The selective phosphoinoside-3-kinase $p 110 \bumpeq$ Inhibitor IPI-3063 potently suppresses B cell survival, proliferation, and differentiation. Frontiers in Immunology, 8, 747.

Consolaro, F., Ghaem-Maghami, S., Bortolozzi, R., Zona, S., Khongkow, M., Basso, G., ... Lam, E. W. (2015). FOXO3a and posttranslational modifications mediate glucocorticoid sensitivity in B-ALL. Molecular Cancer Research, 13, 1578-1590.

Crazzolara, R., Bradstock, K. F., \& Bendall, L. J. (2009). RAD001 (Everolimus) induces autophagy in acute lymphoblastic leukemia. Autophagy, 5, 727-728.

Cutler, J. A., Tahir, R., Sreenivasamurthy, S. K., Mitchell, C., Renuse, S., Nirujogi, R. S., ... Pandey, A. (2017). Differential signaling through p190 and p210 BCR-ABL fusion proteins revealed by interactome and phosphoproteome analysis. Leukemia, 31, 1513-1524.

Daver, N., Boumber, Y., Kantarjian, H., Ravandi, F., Cortes, J., Rytting, M. E., ... Konopleva, M. (2015). A Phase I/II study of the mTOR inhibitor everolimus in combination with hyperCVAD chemotherapy in patients with relapsed/refractory acute lymphoblastic leukemia. Clinical Cancer Research, 21, 2704-2714.

Deininger, M. W., Goldman, J. M., Melo, J. V. (2000). The molecular biology of chronic myeloid leukemia. Blood, 96, 3343-3356.

Deynoux, M., Sunter, N., Herault, O., \& Mazurier, F. (2016). Hypoxia and hypoxia-inducible factors in leukemias. Frontiers in Oncology, 6, 41.

Dias, A., Kenderian, S. J., Westin, G. F., \& Litzow, M. R. (2016). Novel Therapeutic strategies in acute lymphoblastic leukemia. Current Hematologic Malignancy Reports, 11, 253-264.

Ding, J., Romani, J., Zaborski, M., MacLeod, R. A., Nagel, S., Drexler, H. G., \& Quentmeier, H. (2013). Inhibition of PI3 K/mTOR overcomes nilotinib resistance in BCR-ABL1 positive leukemia cells through translational down-regulation of MDM2. PLoS ONE, 8, e83510.

Dunlop, E. A., \& Tee, A. R. (2009). Mammalian target of rapamycin complex 1: Signalling inputs, substrates and feedback mechanisms. Cellular Signalling, 21, 827-835.

Engelman, J. A., Luo, J., \& Cantley, L. C. (2006). The evolution of phosphatidylinositol 3-kinases as regulators of growth and metabolism. Nature Reviews Genetics, 7, 606-619.

Eswaran, J., Sinclair, P., Heidenreich, O., Irving, J., Russell, L. J., Hall, A., ... Vormoor, J. (2015). The pre-B-cell receptor checkpoint in acute lymphoblastic leukaemia. Leukemia, 29, 1623-1631.

Evangelisti, C., Cappellini, A., Oliveira, M., Fragoso, R., Barata, J. T., Bertaina, A., ... Evangelisti, C. (2018). Phosphatidylinositol 3-kinase inhibition potentiates glucocorticoid response in B-cell acute lymphoblastic leukemia. Journal of Cellular Physiology, 233, 1796-1811.

Falasca, M., Hamilton, J. R., Selvadurai, M., Sundaram, K., Adamska, A., \& Thompson, P. E. (2017). Class II phosphoinositide 3-kinases as novel drug targets. Journal of Medicinal Chemistry, 60, 47-65.

Fielding, A. K., Richards, S. M., Chopra, R., Lazarus, H. M., Litzow, M. R., Buck, G., ... Goldstone, A. H. (2007). Outcome of 609 adults after relapse of acute lymphoblastic leukemia (ALL); an MRC UKALL12/ ECOG 2993 study. Blood, 109, 944-950.

Franke, T. F. (2008). PI3K/Akt: Getting it right matters. Oncogene, 27, 6473-6488. 
Frolova, O., Samudio, I., Benito, J. M., Jacamo, R., Kornblau, S. M., Markovic, A., ... Konopleva, M. (2012). Regulation of HIF-1a signaling and chemoresistance in acute lymphocytic leukemia under hypoxic conditions of the bone marrow microenvironment. Cancer Biology \& Therapy, 13, 858-870.

Fu, H., Wang, C., Yang, D., Zhang, X., Wei, Z., Zhu, Z., .. Cai, Q. (2017). Curcumin regulates proliferation, autophagy and apoptosis in gastric cancer cells by affecting PI3K and P53 signaling. Journal of Cellular Physiology, https://doi.org/10.1002/jcp.26190

Fu, J., Hao, L., Tian, Y., Liu, Y., Gu, Y., \& Wu, J. (2018). MiR-199a-3p is involved in estrogen-mediated autophagy through the IGF-1/mTOR pathway in osteocyte-like MLO-Y4 cells. Journal of Cellular Physiology, 233, 2292-2303.

Fuka, G., Kantner, H. P., Grausenburger, R., Inthal, A., Bauer, E., Krapf, G., . . Panzer-Grumayer, R. (2012). Silencing of ETV6/RUNX1 abrogates $\mathrm{PI} 3 \mathrm{~K} / \mathrm{AKT} / \mathrm{mTOR}$ signaling and impairs reconstitution of leukemia in xenografts. Leukemia, 26, 927-933.

Galluzzi, L., Bravo-San Pedro, J. M., Levine, B., Green, D. R., \& Kroemer, G. (2017). Pharmacological modulation of autophagy: Therapeutic potential and persisting obstacles. Nature Reviews Drug Discovery, 16, 487-511.

Geng, H., Hurtz, C., Lenz, K. B., Chen, Z., Baumjohann, D., Thompson, S., . . Muschen, M. (2015). Self-enforcing feedback activation between BCL6 and pre-B cell receptor signaling defines a distinct subtype of acute lymphoblastic leukemia. Cancer Cell, 27, 409-425.

Georgescu, M. M. (2010). PTEN tumor suppressor network in PI3K-Akt pathway control. Genes \& Cancer, 1, 1170-1177.

Goldstone, A. H., Richards, S. M., Lazarus, H. M., Tallman, M. S., Buck, G., Fielding, A. K., .. Rowe, J. M. (2008). In adults with standard-risk acute lymphoblastic leukemia, the greatest benefit is achieved from a matched sibling allogeneic transplantation in first complete remission, and an autologous transplantation is less effective than conventional consolidation/maintenance chemotherapy in all patients: Final results of the International ALL Trial (MRC UKALL XII/ECOG E2993). Blood, 111, 1827-1833.

Gomes, A. M., Soares, M. V., Ribeiro, P., Caldas, J., Povoa, V., Martins, L. R., ... Barata, J. T. (2014). Adult B-cell acute lymphoblastic leukemia cells display decreased PTEN activity and constitutive hyperactivation of PI3K/Akt pathway despite high PTEN protein levels. Haematologica, 99, 1062-1068.

Gotoh, A., Miyazawa, K., Ohyashiki, K., \& Toyama, K. (1994). Potential molecules implicated in downstream signaling pathways of p185BCR$\mathrm{ABL}$ in $\mathrm{Ph}^{+} \mathrm{ALL}$ involve GTPase-activating protein, phospholipase $\mathrm{C}-\gamma 1$, and phosphatidylinositol 3'-kinase. Leukemia, 8, 115-120.

Graham, S. M., Jorgensen, H. G., Allan, E., Pearson, C., Alcorn, M. J., Richmond, L., \& Holyoake, T. L. (2002). Primitive, quiescent, Philadelphia-positive stem cells from patients with chronic myeloid leukemia are insensitive to STI571 in vitro. Blood, 99, 319-325.

Granja, S., Pinheiro, C., Reis, R. M., Martinho, O., \& Baltazar, F. (2015). Glucose addiction in cancer therapy: Advances and drawbacks. Current Drug Metabolism, 16, 221-242.

Guerrero-Zotano, A., Mayer, I. A., \& Arteaga, C. L. (2016). PI3K/AKT/ mTOR: Role in breast cancer progression, drug resistance, and treatment. Cancer Metastasis Reviews, 35, 515-524.

Guichard, S. M., Curwen, J., Bihani, T., D'Cruz, C. M., Yates, J. W., Grondine, M., ... Cosulich, S. C. (2015). AZD2014, an inhibitor of mTORC1 and mTORC2, is highly effective in ER+ breast cancer when administered using intermittent or continuous schedules. Molecular Cancer Therapeutics, 14, 2508-2518.

Guo, Y., Li, Y., Xiang, B., Huang, X. O., Ma, H. B., Wang, F. F., \& Gong, Y. P. (2017). Nutlin-3 plus tanshinone IIA exhibits synergetic antileukemia effect with imatinib by reactivating p53 and inhibiting AKT/mTOR pathway in Ph+ ALL. Biochemical Journal, 474, 4153-4170
Hermida, M. A., Dinesh Kumar, J., \& Leslie, N. R. (2017). GSK3 and its interactions with the $\mathrm{PI} 3 \mathrm{~K} / \mathrm{AKT} / \mathrm{mTOR}$ signalling network. Advances in Biological Regulation, 65, 5-15.

Hirai, H., Sootome, H., Nakatsuru, Y., Miyama, K., Taguchi, S., Tsujioka, K., ... Kotani, H. (2010). MK-2206, an allosteric Akt inhibitor, enhances antitumor efficacy by standard chemotherapeutic agents or molecular targeted drugs in vitro and in vivo. Molecular Cancer Therapeutics, 9, 1956-1967.

Hirase, C., Maeda, Y., Takai, S., \& Kanamaru, A. (2009). Hypersensitivity of $\mathrm{Ph}$-positive lymphoid cell lines to rapamycin: Possible clinical application of mTOR inhibitor. Leukemia Research, 33, 450-459.

Hirsch, E., \& Chiarle, R. (2012). Calming down T cell acute leukemia. Cancer Cell, 21, 449-450.

Huang, J., Dibble, C. C., Matsuzaki, M., \& Manning, B. D. (2008). The TSC1TSC2 complex is required for proper activation of mTOR complex 2 . Molecular and Cellular Biology, 28, 4104-4115.

lacovelli, S., Ricciardi, M. R., Allegretti, M., Mirabilii, S., Licchetta, R., Bergamo, P., ... Tafuri, A. (2015). Co-targeting of Bcl-2 and mTOR pathway triggers synergistic apoptosis in $\mathrm{BH} 3$ mimetics resistant acute lymphoblastic leukemia. Oncotarget, 6, 32089-32103.

Ilagan, E., \& Manning, B. D. (2016). Emerging role of mTOR in the response to cancer therapeutics. Trends in Cancer, 2, 241-251.

Janes, M. R., Limon, J. J., So, L., Chen, J., Lim, R. J., Chavez, M. A., . . Fruman, D. A. (2010). Effective and selective targeting of leukemia cells using a TORC1/2 kinase inhibitor. Nature Medicine, 16, 205-213.

Janes, M. R., Vu, C., Mallya, S., Shieh, M. P., Limon, J. J., Li, L. S., . . Fruman, D. A. (2013). Efficacy of the investigational mTOR kinase inhibitor MLN0128/INK128 in models of B-cell acute lymphoblastic leukemia. Leukemia, 27, 586-594.

Janku, F., McConkey, D. J., Hong, D. S., \& Kurzrock, R. (2011). Autophagy as a target for anticancer therapy. Nature Reviews Clinical Oncology, 8, 528-539.

Jellusova, J., \& Rickert, R. C. (2016). The PI3K pathway in B cell metabolism. Critical Reviews in Biochemistry and Molecular Biology, 51, 359-378.

Jones, J. A., Robak, T., Brown, J. R., Awan, F. T., Badoux, X., Coutre, S., ... Owen, C. (2017). Efficacy and safety of idelalisib in combination with ofatumumab for previously treated chronic lymphocytic leukaemia: An open-label, randomised phase 3 trial. Lancet Haematology, 4, e114-e126.

Kalyanaraman, B. (2017). Teaching the basics of cancer metabolism: Developing antitumor strategies by exploiting the differences between normal and cancer cell metabolism. Redox Biology, 12, 833-842.

Khanna, A., Bhushan, B., Chauhan, P. S., Saxena, S., Gupta, D. K., \& Siraj, F. (2017). High mTOR expression independently prognosticates poor clinical outcome to induction chemotherapy in acute lymphoblastic leukemia. Clinical and Experimental Medicine, https://doi.org/10.1007/ s10238-017-0478-x

Kharas, M. G., \& Fruman, D. A. (2005). ABL oncogenes and phosphoinositide 3-kinase: Mechanism of activation and downstream effectors. Cancer Research, 65, 2047-2053.

Kharas, M. G., Deane, J. A., Wong, S., O'Bosky, K. R., Rosenberg, N., Witte, O. N., \& Fruman, D. A. (2004). Phosphoinositide 3-kinase signaling is essential for $\mathrm{ABL}$ oncogene-mediated transformation of $\mathrm{B}$-lineage cells. Blood, 103, 4268-4275.

Kharas, M. G., Janes, M. R., Scarfone, V. M., Lilly, M. B., Knight, Z. A., Shokat, K. M., \& Fruman, D. A. (2008). Ablation of PI3K blocks BCR-ABL leukemogenesis in mice, and a dual $\mathrm{PI} 3 \mathrm{~K} / \mathrm{mTOR}$ inhibitor prevents expansion of human BCR-ABL+ leukemia cells. Journal of Clinical Investigation, 118, 3038-3050.

Kim, D. H., Sarbassov, D. D., Ali, S. M., King, J. E., Latek, R. R., ErdjumentBromage, H., ... Sabatini, D. M. (2002). MTOR interacts with raptor to form a nutrient-sensitive complex that signals to the cell growth machinery. Cell, 110, 163-175. 
Kohrer, S., Havranek, O., Seyfried, F., Hurtz, C., Coffey, G. P., Kim, E., .. Burger, J. A. (2016). Pre-BCR signaling in precursor B-cell acute lymphoblastic leukemia regulates PI3 K/AKT, FOXO1 and MYC, and can be targeted by SYK inhibition. Leukemia, 30, 1246-1254.

Konopleva, M. Y., Walter, R. B., Faderl, S. H., Jabbour, E. J., Zeng, Z., Borthakur, G., ... Kantarjian, H. M. (2014). Preclinical and early clinical evaluation of the oral AKT inhibitor, MK-2206, for the treatment of acute myelogenous leukemia. Clinical Cancer Research, 20, 2226-2235.

Kruth, K. A., Fang, M., Shelton, D. N., Abu-Halawa, O., Mahling, R., Yang, H., ... Pufall, M. A. (2017). Suppression of B-cell development genes is key to glucocorticoid efficacy in treatment of acute lymphoblastic leukemia. Blood, 129, 3000-3008.

Kuwatsuka, Y., Minami, M., Minami, Y., Sugimoto, K., Hayakawa, F., Miyata, Y., ... Naoe, T. (2011). The mTOR inhibitor, everolimus (RAD001), overcomes resistance to imatinib in quiescent $\mathrm{Ph}$-positive acute lymphoblastic leukemia cells. Blood Cancer Journal, 1(e), 17.

Lafage-Pochitaloff, M., Baranger, L., Hunault, M., Cuccuini, W., Lefebvre, C., Bidet, A., ... Dombret, H. (2017). Impact of cytogenetic abnormalities in adults with $\mathrm{Ph}$-negative B-cell precursor acute lymphoblastic leukemia. Blood, 130, 1832-1844.

Lang, S. A., Hackl, C., Moser, C., Fichtner-Feigl, S., Koehl, G. E., Schlitt, H. J., ... Stoeltzing, O. (2010). Implication of RICTOR in the mTOR inhibitormediated induction of insulin-like growth factor-I receptor (IGF-IR) and human epidermal growth factor receptor-2 (Her2) expression in gastrointestinal cancer cells. Biochimica et Biophysica Acta, 1803, 435-442.

Levy, D. S., Kahana, J. A., \& Kumar, R. (2009). AKT inhibitor, GSK690693, induces growth inhibition and apoptosis in acute lymphoblastic leukemia cell lines. Blood, 113, 1723-1729.

Lis, P., Dylag, M., Niedzwiecka, K., Ko, Y. H., Pedersen, P. L., Goffeau, A., \& Ulaszewski, S. (2016). The HK2 dependent "Warburg effect" and mitochondrial oxidative phosphorylation in cancer: Targets for effective therapy with 3-bromopyruvate. Molecules, 21, E1730.

Liu, P., Gan, W., Chin, Y. R., Ogura, K., Guo, J., Zhang, J., . . W Wei, W. (2015). Ptdlns(3,4,5)P3-Dependent activation of the mTORC2 kinase complex. Cancer Discovery, 5, 1194-1209.

Liu, X., Wang, A., Liang, X., Liu, J., Zou, F., Chen, C., ... Liu, Q. (2016). Simultaneous inhibition of $\mathrm{Vps} 34$ kinase would enhance $\mathrm{PI} 3 \mathrm{~K} \bumpeq$ inhibitor cytotoxicity in the B-cell malignancies. Oncotarget, 7, 53515-53525.

Ma, X. M., \& Blenis, J. (2009). Molecular mechanisms of mTOR-mediated translational control. Nature Reviews Molecular Cell Biology, 10, 307-318.

Malagola, M., Papayannidis, C., \& Baccarani, M. (2016). Tyrosine kinase inhibitors in $\mathrm{Ph}^{+}$acute lymphoblastic leukaemia: Facts and perspectives. Annals of Hematology, 95(5), 681-693.

Manning, B. D., \& Toker, A. (2017). AKT/PKB signaling: Navigating the network. Cell, 169, 381-405.

Martini, M., De Santis, M. C., Braccini, L., Gulluni, F., \& Hirsch, E. (2014). $\mathrm{PI} 3 \mathrm{~K} / \mathrm{AKT}$ signaling pathway and cancer: An updated review. Annals of Medicine, 46, 372-383.

Maude, S. L., Tasian, S. K., Vincent, T., Hall, J. W., Sheen, C., Roberts, K. G., ... Teachey, D. T. (2012). Targeting JAK1/2 and mTOR in murine xenograft models of Ph-like acute lymphoblastic leukemia. Blood, 120, 3510-3518.

Memmott, R. M., \& Dennis, P. A. (2009). Akt-dependent and-independent mechanisms of mTOR regulation in cancer. Cellular Signalling, 21 , 656-664.

Millis, S. Z., Ikeda, S., Reddy, S., Gatalica, Z., \& Kurzrock, R. (2016). Landscape of phosphatidylinositol-3-kinase pathway alterations across 19784 diverse solid tumors. JAMA Oncology, 2, 1565-1573.

Morishita, N., Tsukahara, H., Chayama, K., Ishida, T., Washio, K., Miyamura, T., ... Morishima, T. (2012). Activation of Akt is associated with poor prognosis and chemotherapeutic resistance in pediatric B-precursor acute lymphoblastic leukemia. Pediatric Blood \& Cancer, 59, 83-89.
Moscetti, L., Vici, P., Gamucci, T., Natoli, C., Cortesi, E., Marchetti, P., .. Ruggeri, E. M. (2016). Safety analysis, association with response and previous treatments of everolimus and exemestane in 181 metastatic breast cancer patients: A multicenter Italian experience. Breast, 29, 96-101.

Nemes, K., Sebestyen, A., Mark, A., Hajdu, M., Kenessey, I., Sticz, T., ... Csoka, M. (2013). Mammalian target of rapamycin (mTOR) activity dependent phospho-protein expression in childhood acute lymphoblastic leukemia (ALL). PLoS ONE, 8(e), 59335.

Neri, L. M., Cani, A., Martelli, A. M., Simioni, C., Junghanss, C., Tabellini, G., .. Capitani, S. (2014). Targeting the PI3K/Akt/mTOR signaling pathway in B-precursor acute lymphoblastic leukemia and its therapeutic potential. Leukemia, 28, 739-748.

Ness, K. K., Armenian, S. H., Kadan-Lottick, N., \& Gurney, J. G. (2011). Adverse effects of treatment in childhood acute lymphoblastic leukemia: General overview and implications for long-term cardiac health. Expert Review of Hematology, 4, 185-197.

Ofran, Y., \& Izraeli, S. (2017). BCR-ABL (Ph)-like acute leukemiaPathogenesis, diagnosis and therapeutic options. Blood Reviews, 31, 11-16.

Oliveira, M. L., Akkapeddi, P., Alcobia, I., Almeida, A. R., Cardoso, B. A., Fragoso, R., ... Barata, J. T. (2017). From the outside, from within: Biological and therapeutic relevance of signal transduction in T-cell acute lymphoblastic leukemia. Cellular Signalling, 38, 10-25.

Oshiro, N., Yoshino, K., Hidayat, S., Tokunaga, C., Hara, K., Eguchi, S., ... Yonezawa, K. (2004). Dissociation of raptor from mTOR is a mechanism of rapamycin-induced inhibition of mTOR function. Genes to Cells, 9 , 359-366.

Pal, S. K., \& Quinn, D. I. (2013). Differentiating mTOR inhibitors in renal cell carcinoma. Cancer Treatment Reviews, 39, 709-719.

Pearce, L. R., Komander, D., \& Alessi, D. R. (2010). The nuts and bolts of AGC protein kinases. Nature Reviews Molecular Cell Biology, 11, 9-22.

Peng, C., Chen, Y., Yang, Z., Zhang, H., Osterby, L., Rosmarin, A. G., \& Li, S. (2010). PTEN is a tumor suppressor in CML stem cells and BCR-ABLinduced leukemias in mice. Blood, 115, 626-635.

Petit, C., Gouel, F., Dubus, I., Heuclin, C., Roget, K., \& Vannier, J. P. (2016). Hypoxia promotes chemoresistance in acute lymphoblastic leukemia cell lines by modulating death signaling pathways. BMC Cancer, 16, 746.

Pons-Tostivint, E., Thibault, B., \& Guillermet-Guibert, J. (2017). Targeting $\mathrm{PI} 3 \mathrm{~K}$ signaling in combination cancer therapy. Trends in Cancer, 3, 454-469.

Pui, C. H., \& Evans, W. E. (2006). Treatment of acute lymphoblastic leukemia. New England Journal of Medicine, 354, 166-178.

Pui, C. H., Relling, M. V., \& Downing, J. R. (2004). Acute lymphoblastic leukemia. New England Journal of Medicine, 350, 1535-1548.

Pui, C. H., Pei, D., Campana, D., Cheng, C., Sandlund, J. T., Bowman, W. P., ... Evans, W. E. (2014). A revised definition for cure of childhood acute lymphoblastic leukemia. Leukemia, 28, 2336-2343.

Reckel, S., Hamelin, R., Georgeon, S., Armand, F., Jolliet, Q., Chiappe, D., .. . Hantschel, O. (2017). Differential signaling networks of Bcr-Abl p210 and p190 kinases in leukemia cells defined by functional proteomics. Leukemia, 31, 1502-1512.

Ren, X., Pan, X., Zhang, Z., Wang, D., Lu, X., Li, Y., ... Ding, K. (2013). Identification of GZD824 as an orally bioavailable inhibitor that targets phosphorylated and nonphosphorylated breakpoint cluster regionAbelson (Bcr-Abl) kinase and overcomes clinically acquired mutationinduced resistance against imatinib. Journal of Medicinal Chemistry, 56, 879-894.

Reshmi, S. C., Harvey, R. C., Roberts, K. G., Stonerock, E., Smith, A., Jenkins, H., ... Hunger, S. P. (2017). Targetable kinase gene fusions in high-risk B-ALL: A study from the Children's Oncology Group. Blood, 129, 3352-3361.

Rhodes, N., Heerding, D. A., Duckett, D. R., Eberwein, D. J., Knick, V. B., Lansing, T. J., ... Kumar, R. (2008). Characterization of an Akt kinase 
inhibitor with potent pharmacodynamic and antitumor activity. Cancer Research, 68, 2366-2374.

Rodgers, S. J., Ferguson, D. T., Mitchell, C. A., \& Ooms, L. M. (2017) Regulation of $\mathrm{PI} 3 \mathrm{~K}$ effector signalling in cancer by the phosphoinositide phosphatases. Bioscience Reports, 37, BSR 20160432.

Rodon, J., \& Tabernero, J. (2017). Improving the armamentarium of PI3K inhibitors with isoform-selective agents: A new light in the darkness. Cancer Discovery, 7, 666-669.

Romana, S. P., Mauchauffe, M., Le Coniat, M., Chumakov, I., Le Paslier, D., Berger, R., \& Bernard, O. A. (1995). The $t(12 ; 21)$ of acute lymphoblastic leukemia results in a tel-AML1 gene fusion. Blood, 85 3662-3670.

Rosner, M., \& Hengstschlager, M. (2008). Cytoplasmic and nuclear distribution of the protein complexes mTORC1 and mTORC2: Rapamycin triggers dephosphorylation and delocalization of the mTORC2 components rictor and sin1. Human Molecular Genetics, 17 2934-2948.

Ruvolo, P. P. (2017). GSK-3 as a novel prognostic indicator in leukemia. Advances in Biological Regulation, 65, 26-35.

Safaroghli-Azar, A., Bashash, D., Sadreazami, P., Momeny, M., \& Ghaffari, S. H. (2017). PI3K-^ inhibition using CAL-101 exerts apoptotic effects and increases doxorubicin-induced cell death in pre-B-acute lymphoblastic leukemia cells. Anti-cancer Drugs, 28, 436-445.

Sattler, M., Salgia, R., Okuda, K., Uemura, N., Durstin, M. A., Pisick, E., ... Griffin, J. D. (1996). The proto-oncogene product p120CBL and the adaptor proteins CRKL and c-CRK link c-ABL, p190BCR/ABL and p210BCR/ABL to the phosphatidylinositol-3' kinase pathway. Oncogene, 12, 839-846.

Saunders, P., Cisterne, A., Weiss, J., Bradstock, K. F., \& Bendall, L. J. (2011). The mammalian target of rapamycin inhibitor RAD001 (everolimus) synergizes with chemotherapeutic agents, ionizing radiation and proteasome inhibitors in pre-B acute lymphocytic leukemia. Haematologica, 96, 69-77.

Saunders, P. O., Weiss, J., Welschinger, R., Baraz, R., Bradstock, K. F., \& Bendall, L. J. (2013). RAD001 (everolimus) induces dose-dependent changes to cell cycle regulation and modifies the cell cycle response to vincristine. Oncogene, 32, 4789-4797.

Schult, C., Dahlhaus, M., Glass, A., Fischer, K., Lange, S., Freund, M., \& Junghanss, C. (2012). The dual kinase inhibitor NVP-BEZ235 in combination with cytotoxic drugs exerts anti-proliferative activity towards acute lymphoblastic leukemia cells. Anticancer Research, 32, 463-474.

Shah, O. J., Wang, Z., \& Hunter, T. (2004). Inappropriate activation of the TSC/Rheb/mTOR/S6K cassette induces IRS1/2 depletion, insulin resistance, and cell survival deficiencies. Current Biology, 14, 1650-1656.

Shahbazian, D., Parsyan, A., Petroulakis, E., Topisirovic, I., Martineau, Y., Gibbs, B. F., ... Sonenberg, N. (2010). Control of cell survival and proliferation by mammalian eukaryotic initiation factor 4B. Molecular and Cellular Biology, 30, 1478-1485.

Shen, G., Ren, H., Qiu, T., Zhang, Z., Zhao, W., Yu, X., ... Jiang, X. (2018). Mammalian target of rapamycin as a therapeutic target in osteoporosis. Journal of Cellular Physiology, 233, 3929-3944.

Shochat, C., Tal, N., Bandapalli, O. R., Palmi, C., Ganmore, I., te Kronnie, G., ... Izraeli, S. (2011). Gain-of-function mutations in interleukin-7 receptor-a (IL7R) in childhood acute lymphoblastic leukemias. Journal of Experimental Medicine, 208, 901-908.

Shochat, C., Tal, N., Gryshkova, V., Birger, Y., Bandapalli, O. R., Cazzaniga, G., .. Izraeli, S. (2014). Novel activating mutations lacking cysteine in type I cytokine receptors in acute lymphoblastic leukemia. Blood, 124 106-110.

Simioni, C., Cani, A., Martelli, A. M., Zauli, G., Tabellini, G., McCubrey, J., .. . Neri, L. M. (2014). Activity of the novel mTOR inhibitor Torin-2 in Bprecursor acute lymphoblastic leukemia and its therapeutic potential to prevent Akt reactivation. Oncotarget, 5, 10034-10047.
Siska, P. J., van der Windt, G. J., Kishton, R. J., Cohen, S., Eisner, W., Maclver, N. J., ... Rathmell, J. C. (2016). Suppression of Glut1 and glucose metabolism by decreased Akt/mTORC1 signaling drives $\mathrm{T}$ cell impairment in B cell leukemia. Journal of Immunology, 197 2532-2540.

Skorski, T., Kanakaraj, P., Nieborowska-Skorska, M., Ratajczak, M. Z., Wen, S. C., Zon, G., ... Calabretta, B. (1995). Phosphatidylinositol-3 kinase activity is regulated by $B C R / A B L$ and is required for the growth of Philadelphia chromosome-positive cells. Blood, 86, 726-736.

Sparks, C. A., \& Guertin, D. A. (2010). Targeting mTOR: Prospects for mTOR complex 2 inhibitors in cancer therapy. Oncogene, 29, 3733-3744.

Sriburi, R., Jackowski, S., Mori, K., \& Brewer, J. W. (2004). XBP1: A link between the unfolded protein response, lipid biosynthesis, and biogenesis of the endoplasmic reticulum. Journal of Cell Biology, 167, 35-41.

Stefanzl, G., Berger, D., Cerny-Reiterer, S., Blatt, K., Eisenwort, G., Sperr, W. R., ... Valent, P. (2017). The pan-BCL-2-blocker obatoclax (GX15070) and the PI3-kinase/mTOR-inhibitor BEZ235 produce cooperative growth-inhibitory effects in ALL cells. Oncotarget, 8, 67709-67722.

Sugiyama, M., Yoshizumi, T., Yoshida, Y., Bekki, Y., Matsumoto, Y., Yoshiya, S., ... Maehara, Y. (2017). P62 promotes amino acid sensitivity of mTOR pathway and hepatic differentiation in adult liver stem/progenitor cells. Journal of Cellular Physiology, 232, 2112-2124.

Tasian, S. K., Doral, M. Y., Borowitz, M. J., Wood, B. L., Chen, I. M., Harvey, R. C., ... Loh, M. L. (2012). Aberrant STAT5 and PI3K/mTOR pathway signaling occurs in human CRLF2-rearranged B-precursor acute lymphoblastic leukemia. Blood, 120, 833-842.

Tasian, S. K., Teachey, D. T., Li, Y., Shen, F., Harvey, R. C., Chen, I. M., .. Grupp, S. A. (2017). Potent efficacy of combined PI3K/mTOR and JAK or $A B L$ inhibition in murine xenograft models of $\mathrm{Ph}$-like acute lymphoblastic leukemia. Blood, 129, 177-187.

Teachey, D. T., Obzut, D. A., Cooperman, J., Fang, J., Carroll, M., Choi, J. K., ... Grupp, S. A. (2006). The mTOR inhibitor CCl-779 induces apoptosis and inhibits growth in preclinical models of primary adult human ALL. Blood, 107, 1149-1155.

Tolcher, A. W., LoRusso, P., Arzt, J., Busman, T. A., Lian, G., Rudersdorf, N. S., .. Rosen, L. S. (2015). Safety, efficacy, and pharmacokinetics of navitoclax (ABT-263) in combination with irinotecan: Results of an open-label, phase 1 study. Cancer Chemotherapy and Pharmacology, 76, 1041-1049.

Tovar, C. F., Zeron, H. M., Romero, M. D., Sanchez, Y. V., \& Romero, I. T. (2016). Glycogen synthase kinase-3b (GSK-3b) and nuclear factor kappa-B (NFKB) in childhood acute lymphoblastic leukemia. Advances in Clinical and Experimental Medicine, 25, 1139-1147.

Tran, T. H., \& Loh, M. L. (2016). Ph-like acute lymphoblastic leukemia. Hematology, 2016, 561-566.

Ultimo, S., Simioni, C., Martelli, A. M., Zauli, G., Evangelisti, C., Celeghini, C., ... Neri, L. M. (2017). PI3K isoform inhibition associated with anti BcrAbl drugs shows in vitro increased anti-leukemic activity in Philadelphia chromosome-positive B-acute lymphoblastic leukemia cell lines. Oncotarget, 8, 23213-23227.

van der Sligte, N. E., Scherpen, F. J., Meeuwsen-de Boer, T. G., Lourens, H. J., Ter Elst, A., Diks, S. H., ... de Bont, E. S. (2015). Kinase activity profiling reveals active signal transduction pathways in pediatric acute lymphoblastic leukemia: A new approach for target discovery. Proteomics, 15, 1245-1254.

Vanhaesebroeck, B., Guillermet-Guibert, J., Graupera, M., \& Bilanges, B. (2010). The emerging mechanisms of isoform-specific PI3K signalling. Nature Reviews Molecular Cell Biology, 11, 329-341.

Vanhaesebroeck, B., Vogt, P. K., \& Rommel, C. (2010). PI3K: From the bench to the clinic and back. Current Topics in Microbiology and Immunology, $347,1-19$

Vo, T. T., Lee, J. S., Nguyen, D., Lui, B., Pandori, W., Khaw, A., ... Fruman, D. A. (2017). MTORC1 inhibition induces resistance to methotrexate 
and 6-mercaptopurine in $\mathrm{Ph}+$ and Ph-like B-ALL. Molecular Cancer Therapeutics, 16, 1942-1953.

Wang, L., Fortney, J. E., \& Gibson, L. F. (2004). Stromal cell protection of Blineage acute lymphoblastic leukemic cells during chemotherapy requires active Akt. Leukemia Research, 28, 733-742.

Wang, W. Z., Lin, X. H., Pu, Q. H., Liu, M. Y., Li, L., Wu, L. R., .. . Jin, X. B. (2014). Targeting miR-21 sensitizes $\mathrm{Ph}^{+}$ALL SUP-B15 cells to imatinibinduced apoptosis through upregulation of PTEN. Biochemical and Biophysical Research Communications, 454, 423-428.

Wang, N., Zhang, Q., Luo, L., Ning, B., \& Fang, Y. (2018). B-asarone inhibited cell growth and promoted autophagy via P53/Bcl-2/Bclin-1 and P53/ AMPK/mTOR pathways in Human Glioma U251 cells. Journal of Cellular Physiology, 233, 2434-2443.

Won, S. J., Yen, C. H., Lin, T. Y., Jiang-Shieh, Y. F., Lin, C. N., Chen, J. T., \& Su, C. L. (2018). Autophagy mediates cytotoxicity of human colorectal cancer cells treated with garcinielliptone FC. Journal of Cellular Physiology, 233, 497-505.

Wong, J., Welschinger, R., Hewson, J., Bradstock, K. F., \& Bendall, L. J. (2014). Efficacy of dual PI-3K and mTOR inhibitors in vitro and in vivo in acute lymphoblastic leukemia. Oncotarget, 5, 10460-10472.

Xie, Y., Naizabekov, S., Chen, Z., \& Tokay, T. (2016). Power of PTEN/AKT: Molecular switch between tumor suppressors and oncogenes. Oncology Letters, 12, 375-378.

Xing, H., Yang, X., Liu, T., Lin, J., Chen, X., \& Gong, Y. (2012). The study of resistant mechanisms and reversal in an imatinib resistant $\mathrm{Ph}^{+}$acute lymphoblastic leukemia cell line. Leukemia Research, 36, 509-513.

Xu, X., Sarikas, A., Dias-Santagata, D. C., Dolios, G., Lafontant, P. J., Tsai, S. C., ... Pan, Z. Q. (2008). The CUL7 E3 ubiquitin ligase targets insulin receptor substrate 1 for ubiquitin-dependent degradation. Molecular Cell, 30, 403-414.

Yang, X., Lin, J., Gong, Y., Ma, H., Shuai, X., Zhou, R., ... He, G. (2012). Antileukaemia effect of rapamycin alone or in combination with daunorubicin on $\mathrm{Ph}^{+}$acute lymphoblastic leukaemia cell line. Hematological Oncology, 30, 123-130.

Yang, X., He, G., Gong, Y., Zheng, B., Shi, F., Shi, R., \& Yang, X. (2014). Mammalian target of rapamycin inhibitor rapamycin enhances anti-leukemia effect of imatinib on $\mathrm{Ph}^{+}$acute lymphoblastic leukemia cells. European Journal of Haematology, 92, 111-120.

Yates, J. W., Dudley, P., Cheng, J., D'Cruz, C., \& Davies, B. R. (2015). Validation of a predictive modeling approach to demonstrate the relative efficacy of three different schedules of the AKT inhibitor AZD5363. Cancer Chemotherapy and Pharmacology, 76, 343-356.

Yu, X., Long, Y. C., \& Shen, H. M. (2015). Differential regulatory functions of three classes of phosphatidylinositol and phosphoinositide 3-kinases in autophagy. Autophagy, 11, 1711-1728.

Yun, S., Vincelette, N. D., Knorr, K. L., Almada, L. L., Schneider, P. A., Peterson, K. L., ... Kaufmann, S. H. (2016). 4EBP1/c-MYC/PUMA and NF-kB/EGR1/BIM pathways underlie cytotoxicity of mTOR dual inhibitors in malignant lymphoid cells. Blood, 127, 2711-2722.

Zeng, Q., Qin, S., Zhang, H., Liu, B., Qin, J., Wang, X., ... Chen, L. (2018). Rapamycin attenuates BAFF-extended proliferation and survival via disruption of mTORC1/2 signaling in normal and neoplastic B-lymphoid cells. Journal of Cellular Physiology, 233, 516-529.

How to cite this article: Simioni C, Martelli AM, Zauli G, et al. Targeting the phosphatidylinositol 3-kinase/Akt/ mechanistic target of rapamycin signaling pathway in Blineage acute lymphoblastic leukemia: An update. J Cell Physiol. 2018;233:6440-6454. https://doi.org/10.1002/jcp.26539 